\title{
Does analytical sociology practice what it preaches? An assessment of analytical sociology through the Merton award
}

\author{
Gianluca Manzo ${ }^{1}$
}

\section{INTRODUCTION}

Mechanism-based explanations are at heart of analytical sociology. If one considers Hedström and Swedberg's article, published in Acta Sociologica in 1996, as the beginning of the explicit and systematic elaboration of a research program in sociology based on the concept of social mechanism, the field of analytical sociology has been under debate for about twenty-five years. This time is sufficiently long to appreciate, on the one hand, how the principles and methods of analytical sociology have evolved on a programmatic level, while on the other hand questioning whether analytical sociology practices what it preaches. This second part of the exercise seems particularly urgent. Some have argued that, while "the proof of the pudding is always in the eating", analytical sociology spends more time discussing epistemological and meta-theoretical issues rather than applying its programmatic principles and methods to substantive problems (Edling and Rydgren 2016: 1139).

In this chapter, I first synthetically reconstruct the progressive evolution of analytical sociology on a meta-theoretical level and show that analytical sociology is currently predicated under various programs and sub-programs (section 1). Then, with the aim to assess what analytical sociology has delivered so far in practice, I take these programmatic variations as a benchmark and compare them against a specific set of journal articles, namely those having received the Merton award (see Table I.1), the prize that the International Network of Analytical Sociology first gave in 2013 in recognition of the best article on analytical sociology.

In particular, I will go through five steps. After preliminarily describing some formal signs of the Merton awarded article's academic visibility (section 2), I first investigate the extent to which these articles explicitly referred to analytical sociology and mechanism-based explanations to frame their substantive investigations (section 3). Second, I investigate whether the Merton awarded articles conformed to analytical sociology's requirement of focusing on well-defined macroscopic patterns/dynamics with a clear explanatory goal in mind (section 4). Third, I reconstruct the explanatory machinery of each Merton awarded article and assess the extent to which it conformed to analytical sociology's requirement of explaining by formulating well-specified models of mechanisms, thus also assessing how the concept of mechanism is understood within these works (section 5). Fourth, with the specific aim in mind of establishing the extent to which particular methods dominate analytical sociology's empirical works, I investigate how the Merton awarded articles combined data and methods to prove

\footnotetext{
1 I would like to thank Viviana Amati, Andreas Flache, and Werner Raub for providing helpful written comments on an early version of this chapter. The usual disclaimers apply.
} 


\section{Research handbook on analytical sociology}

the empirical plausibility of the proposed mechanisms (section 6). Finally, with some critiques of analytical sociology in mind, I consider again the explanatory mechanism formulated by each Merton awarded article and investigate whether actors' actions are framed within rational choice theories (section 7.1) as well as the extent to which the proposed mechanisms are designed by using "anomalous" elements, i.e. concepts, theories, or broader research perspectives that analytical sociology's manifestos either criticized or did not explicitly include within the analytical sociology's basic toolbox (section 7.2).

The most general result of this analysis was that, although the authors of the Merton awarded articles rarely referred to analytical sociology's manifestos explicitly, they applied in practice all the theoretical principles and, to a large extent, the methodological principles too; those manifestos progressively codified with increasing explicitness. The analysis also revealed that analytical sociology's substantive investigations are less engaged with rational choice theories, but are characterized by a higher level of theoretical pluralism than analytical sociology's critics are usually ready to admit.

In conclusion, I build on these results (summarized in section 8) to suggest five guidelines for the further development of analytical sociology and explain how the present Research Handbook intends to contribute to this process.

\section{PROGRAMS AND SUB-PROGRAMS IN ANALYTICAL SOCIOLOGY}

Over the last twenty-five years, the principles and the methods of analytical sociology were progressively clarified and codified. The perspective moved from a set of general statements on how to increase the explanatory value of sociological theory to a research strategy clearly articulated around a well-defined sequence of operational steps (section 1.1). This founding stage raised a fair amount of critiques (section 1.2), which led to a new formulation of the analytical sociology's research core, as well as to the awareness that variations now exist in this core (section 1.3). The presence of programs and sub-programs of analytical sociology makes it important to assess empirically how analytical sociology materialized in substantive works that were delivered independently from edited volumes on this perspective (section 1.4).

\subsection{The Founding Stage (1996-2009)}

The very first agenda-setting article where the concept of social mechanism was systematically treated (Hedström and Swedberg 1996) did not even employ the term "analytical sociology". It essentially defended the general claim that well-specified models of mechanisms could help sociological theorizing to escape mere conceptual re-labelling and story-telling and simple descriptions of correlations among variables. Mechanisms were seen as multi-layered chains of events that, by connecting actors' opportunities, desires, and beliefs to the social context in which actors are embedded, dynamically led to (associations of) events at a higher level of abstraction (ibid., 296-8).

Hedström and Swedberg's (1998a) subsequent edited volume demonstrated that this message had the potential to rally a variety of scholars around a common research program, but the specific content of this research program remained relatively unspecified. The term "analytical sociology" only appeared once in Hedström and Swedberg's (1998b, 15) introductory essay. 
The "analytical" approach to social theory they defended essentially consisted of (1) a general claim on the explanatory value of building abstract models of social mechanisms (ibid., 7-11), and (2) a defense of an open version of methodological individualism (ibid., 11-13), and a critique of variable-based sociology (ibid., 15-17). To add concreteness, Hedström and Swedberg (1996: 293-6; 1998b: 17-21) discussed several pieces of research illustrating, in their eyes, the distinctive features of mechanism-based theorizing, namely Merton's selffulfilling prophecy, Granovetter's threshold models, and Coleman's study of the diffusion of innovations through social networks. But this did not translate into a specific and structured research protocol that could have been used to build models of mechanisms, formalize them, and investigate them empirically.

Hedström (2005) constituted an important step into this direction. In this book, the idea of mechanism-based explanation is no longer the focus of the investigation: it became one of the components of "analytical sociology"; in particular, its favorite understanding of explanation (ibid., 2). Analytical sociology is then presented as a set of principles and tools for building this type of explanations and connecting them to empirics.

More particularly, as to principles, Hedström (2005) introduced three new elements: (a) an invitation to balance the abstraction of models of mechanisms with the realism of the assumptions on which they are based (ibid., 3, 62, 65); (b) the requirement of systematically relating the basic components of the individual actions (in particular, beliefs, desires, and opportunities) to the structure of the interactions in which actors are embedded (ibid., 42-56); (c) the imperative of not restricting the hypotheses concerning individuals' action to cost-benefit analysis, utility maximization or optimality reasoning (ibid., 41, 60-6). As to tools, three proposals were made: (a) social networks analysis was seen as a way to describe, on the one hand, aggregate patterns of explanatory interest (ibid., 5, 67) and, on the other hand, specific pieces of more complex models of mechanisms, in particular the relevant interaction structures that may constraint actors' actions (ibid., 76f, 93-8); (b) numerical simulations of agent-based computational models were proposed as the most flexible tool to study the micro-to-macro-transition part of a model of a mechanism, in particular when actors' choices are contingent on interactions with other actors (ibid., 76-87); (c) a specific type of data-driven agent-based computational simulations - where the agents' behavior is based on previously estimated statistical models - were also proposed as a pivotal tool to reach empirically plausible simulated models of social mechanisms (ibid., chapter 6).

However, one must wait for Hedström and Bearman (2009) to see these points translated into a synthetic bullet-pointed research recipe for the first time. After discussing Schelling's segregation model (ibid., 12-13) and more recent works on network topologies formation (ibid., 14-15) as illustrations of analytical sociology's principles and methods, Hedström and Bearman (2009: 16) codified the bulk of the "explanatory strategy" of analytical sociology in the following terms:

1. We start with a clearly delineated social fact that is to be explained.

2. We formulate different hypotheses about relevant micro-level mechanisms.

3. We translate the theoretical hypotheses into computational models.

4. We simulate the models to derive the type of social facts that each micro-level mechanism brings about.

5. We compare the social facts generated by each model with the actually observed outcomes.

Hedström and Bearman (2009: 16) labeled this research strategy "generative methodology" and claimed that "[it] is generally applicable and it is a crucial part of the analytical toolbox". 


\section{Research handbook on analytical sociology}

\subsection{The Critical Effervescence (2007-2014)}

Interestingly, the more clearly analytical sociology's core was specified, the more explicitly and virulently it was criticized. The epistemological, theoretical, and conceptual aspects of this core were abundantly discussed. The concept of mechanism was seen as (a) poorly defined (Gross 2009: 360-2); (b) the epistemological status of a mechanism was judged unclear (Mayntz 2004: 239; Reiss 2007: 166); (c) mechanism-based explanations were considered as necessarily incomplete (Opp 2005: 169; Steel, 2004: 61-4); (d) the opposition between mechanism-based explanations and the covering-law model of explanation were regarded as unconvincing (Opp 2005: 174-7; 2007: 117-18; Norkus 2005: 352-5); (e) analytical sociology's theory of action was judged as substantially equivalent to rational choice theory (Abbott 2007a; Gross 2009: 365-7; Opp 2013). In contrast, the methodological components of the analytical sociology's research program received only rapid comments. In particular, some objected that analytical sociology underestimated the role of multivariate statistical methods (Opp 2007: 121); others observed that the concept of mechanism in fact is ultimately reducible to that of variable (Morgan 2005: 31); still others regarded the emphasis on computer simulations as excessive (Abbott 2007b: 1; Sawyer 2007: 260). ${ }^{2}$

These commentators shared a common goal. They wanted to question the distinctiveness of analytical sociology. Some were more explicit than others. For instance, Lizardo (2012) claimed that analytical sociology's emphasis on agent-based computer simulations made this perspective soluble within computational social sciences; Little (2012) regarded analytical sociology's emphasis on micro foundation as a sign that analytical sociology was no more than a new brand name for the doctrine of methodological individualism (for a reply, see Barbera 2012; Manzo 2012a). Surprisingly enough, this same view of "the handbooks of analytical sociology" was expressed by Boudon (2012) himself, whom Hedström (2005: 6, 7, 23, 112-3, 145) regarded as one of the pioneers of analytical sociology (for a reply, see Manzo 2012b: 50-7). Demeulenaere (2011: 5) also argued that the main contribution of analytical sociology for contemporary social sciences consisted in avoiding usual "misconceptions" about methodological individualism.

Analytical sociologists recognized the importance of these critiques but they also noted that they were selective. Critics typically focused on one, or a few, theoretical principles of analytical sociology and, when methodological elements were considered, only a few aspects were evoked. For instance, Winship and Morgan (2014: 341, fn. 15) expressed skepticism against "computer simulations" in general, but they did not discuss in detail how analytical sociology proposed to connect them to data. By doing so, analytical sociology's overall picture was lost. The potential benefits of the progressive codification of analytical sociology's core vanished. The analytical sociology's project was integrative and inclusive. Its distinctiveness was to find, in the set of epistemological, theoretical, and methodological elements, that the analytical sociology's manifestos progressively clarified. Instead, the originality evaporated as soon as the parts were isolated from the whole (see Manzo 2011).

\footnotetext{
2 A systematic discussion of these objections can be found in Manzo (2007; 2010: 140ft, 142-57; 2013; 2014 : 15-16) and Ylikoski (2013).
} 


\subsection{A Re-Formulation and New Reactions (2014-)}

To make this point explicit, Manzo (2014: 7-9) further elaborated analytical sociology's principles on the basis of the critiques accumulated over the years and proposed to combine analytical sociology's core meta-theoretical and methodological ingredients within a synthetic set of seven postulates $(\mathrm{P})$ :

P1: use concepts that are as clear and precise as possible to describe both the facts to be explained and the explanatory hypotheses/facts mobilized to explain them, while avoiding all linguistic obscurity and convolutedness;

P2: mobilize the best quantitative and qualitative empirical information available and use the technical tools best suited to describing the facts to be explained;

P3: in order to explain the social outcome(s) described, first formulate a "generative model," that is, a model of a (set of) mechanism(s), where a mechanism is a set of entities and activities likely to trigger a sequence of events (i.e., a process) likely to bring about the outcome(s);

P4: in order to formulate the "generative model," provide a realistic description of the relevant micro-level entities (P4a) and activities (P4b) assumed to be at work, as well as of the structural interdependencies $(\mathrm{P} 4 \mathrm{c})$ in which these entities are embedded and their activities unfold;

P5: in order rigorously to assess the internal consistency of the "generative model" and to determine its high-level consequences, translate the "generative model" into an agent-based computational model;

P6: in order to assess the generative sufficiency of the mechanisms postulated, compare the agentbased computational model's high-level consequences with the empirical description of the facts to be explained;

P7: in order to prove that the hypothesized micro- and network-level assumptions are not only generative sufficient but also empirically grounded, inject as much individual- and relational-level quantitative, qualitative, and/or experimental data as possible into the agent-based computational model and re-analyze its behavior and high-level consequences.

Manzo (2014: 29-34) carefully explained why agent-based computational models should be especially considered for the formal deduction of the macroscopic consequences of a model of a mechanism but, at the same time, he explicitly recognized that P1-P7 should not be seen as a rigid research sequence one must go through in any single work (ibid., 10). The proposed list of theoretical and methodological options should instead be interpreted as a logically well-organized set of "negative heuristics" telling us what research path should be avoided and of "positive heuristics" telling us what paths should be pursued. The sui generis nature of analytical sociology, Manzo argued, is to advise us to keep in mind the entire set of "heuristics" even if, for a variety of practical reasons, it may not be possible, or even not necessary, to perform all the requisite operations within a given piece of research (ibid., 10).

Manzo's re-formulation of analytical sociology's principles and methods had the interest of forcing scholars to tell explicitly what postulates they are ready to accept as foundational for analytical sociology. As a by-product, it became apparent that analytical sociology is now predicated under different programmatic regimes, depending on what principles are the most valued by a given author.

In particular, Kalter and Kroneberg (2014: 107) recognized that Manzo's set of principles:

[...] allows us to clarify, again, the common denominator of explanatory and analytical sociology, as scholars in both traditions generally agree on principles P1-P4: emphasising clarity and precision, carefully establishing the explanandum, and formulating a generative model of the underlying mecha- 


\section{Research handbook on analytical sociology}

nisms along the lines of structural individualism", but they advised not to give a "truly foundational status" to methodological principles "[...] P5-P6 [...] as they are all about agent-based models and their empirical testing and calibration $[\ldots] "$ ".

Kalter and Kroneberg (2014: 108) preferred instead not to restrict programmatically the way of formalizing and testing generative models of social mechanisms to any particular methods or research design. Similarly, Bouvier (2018: 19) observed that:

[...] Manzo highlights a very specific sub-program of analytical sociology (p.6), which explicitly emphasizes the role of agent-based computational modeling (pp.7-10) and, generally speaking, formal modeling (in particular graph theory).

Bouvier did not contest "[...] the legitimacy of such a sub-program [...]", but he recommended to put more emphasis on "the issues of rationality and intentionality", thus valuing analytical sociology's general contribution to action theory more than its empirical application through specific methodologies.

With respect to action theory itself, Kroneberg and Tutic (this volume) also recognized the existence within analytical sociology of a "weak" and a "strong program", the former being agnostic about the action theory that should inform theoretical model building (as illustrated by Manzo's postulate 4, which is silent about how to depict the behavior of the micro-level entities under exam), whereas the latter still believed in the importance of seeking a general theory of action to be used in an axiomatic way (see also Hedström this volume).

Keuschnigg et al.'s (2018) recent analysis of the potential relationships between analytical sociology and the larger field of computational social sciences also contains traces of the co-existence within current analytical sociology of a general program focusing on generic meta-theoretical principles with a specific sub-program emphasizing particular methods to connect theory and empirics. In particular, Keuschnigg and colleagues described "[...] the core defining characteristics of AS [...] under three headings related to the importance of explanation, the modeling of dynamic social processes, and realism [...]" (ibid., 4), and, when giving details on the second elements, they noted that:

the guiding idea of AS is that we explain collective or aggregate outcomes: (1) by developing a model - possibly a simulation model - that shows how individuals can bring about such an outcome, and (2) by empirically demonstrating that the proposed model indeed is plausible in the specific case. (ibid., 5; emphasis added)

Thus, again, computer simulations are presented as an ideal goal for analytical sociology, not as a necessary ingredient. ${ }^{3}$

3 It should also be noted that Keuschnigg et al. (2018: 8-10) argued that the added value of analytical sociology for computational social sciences consists in its emphasis on building explanatory models of mechanisms rather than on tools. The latter- among which they included agent-based simulations, macro-oriented experiments, counterfactual approaches to causality, and inductive analyses using machine learning techniques on more or less unstructured data - are brought to analytical sociology from computational social sciences (ibid., 6-8, 11). 


\subsection{Programs and Sub-Programs in Substantive Works}

But how were these programmatic variations materialized in substantive works inspired by analytical sociology? Some regretted that the movement of progressive codification of analytical sociology's principles and methods was disconnected from their applications. Edling and Rydgren (2016: 1139) overtly denounced this limitation, and claimed

[...] the literature on social mechanisms is still too preoccupied with intratheoretical and metatheoretical discussions, and we find very few empirical applications [...]; the proof of the pudding is always in the eating and we strongly believe that examples of good empirical research, not theoretical manifestos, are what drive the evolution of social science.

To advance in that direction, Edling and Rydgren (2016: 1141-4) collected six mechanismoriented pieces of empirical research, compared them, and concluded that, although these pieces did not share the same "definition of what a mechanism actually is" (ibid., 1140), they illustrated four fundamental points of the social mechanism approach: (1) they all started with a research question that "identify a real-world phenomenon and ask a pertinent question that demands explanation"; (2) they identified mechanisms at different levels all involving some form of micro foundation and reference to social interactions; (3) the proposed mechanisms were not exclusively associated to "one particular model of man the way rational choice theory does" (ibid., 1140); (4) various types of data were used to show the explanatory relevance of the proposed mechanism - a point, they emphasized, that suggests that there is no reason to mix up the broader social mechanism approach with a narrower focus on "computer-based simulations".

In fact, analytical sociology's manifestos had already attempted to combine principles' elaboration with substantive research. In addition to Manzo's (2014) programmatic chapter discussed, and two other theoretical/methodological essays, Manzo's Analytical Sociology: Actions and Networks edited volume contained thirteen contributions that tried to answer well-defined empirical research questions. Among them, three studies relied on mathematical and/or agent-based computational simulations (without data), whereas ten others differently exploited historical data, survey data, geo-referenced information, digital traces, and/or lab or in-field experiments (see Manzo 2014: 12, 40-1). Edling and Rygren (2016: 1144, f. 1) surprisingly downplayed this fact and quickly claimed instead that "[...] although the volume edited by Manzo (2014) includes empirical chapters, they are almost exclusively preoccupied with simulations". Chattoe-Brown (2014) provided a more accurate analysis of these contributions. His conclusion was highly dismissive, however. In his eyes, with the exception of two studies coming very close to the entire sequence of steps defined by the seven postulates proposed by Manzo, the majority of contributions only focused on "some of these (or less charitably ignore others) with the result that they do not look much different in practice from existing forms of research". Manzo (2014: 10, 40) himself framed each chapter as a variation on the common theme represented by the seven proposed postulates defining analytical sociology's core: the substantive contributions were seen as providing theoretical and/or methodological resources and solutions to develop further and to implement specific elements of the research program. Chattoe-Brown did not accept this approach, and went straightforward to his ultimate goal: similarly, to the discontents with analytical sociology's manifestos I have evoked above, the reviewer wanted to deny that analytical sociology constitutes a "coherent research 


\section{Research handbook on analytical sociology}

programme" that can pretend to be "rigorous in a distinctive way (rather than just being more rigorous than average)".

At present, we have a new resource to assess the extent to which substantive works exist that follow the principles and the methods progressively codified by analytical sociology's manifestos. In 2012, the International Network of Analytical Sociology decided to create the "Robert K. Merton Award" for the best paper in analytical sociology. ${ }_{4}^{4}$ As the prize is awarded once a year at the annual meeting of the research network, eight articles have been awarded so far; in addition, three articles received an honorable mention in 2013, 2015, and 2020, respectively (see Table I.1). Compared to studies that are included within a special issue or an edited volume on analytical sociology, the interest of these eleven articles to evaluate analytical sociology at work is that they are not written to meet a specific invitation related to the endeavor of building analytical sociology. They were submitted to regular journals, and then submitted to the prize committee by their author(s) and/or nominated by third-party colleagues; they were finally evaluated by changing, and composite, prize committee members (see Table I.1). For this reason, in my view, the Merton award winning articles are an interesting source to assess whether or not analytical sociology has a core. Let me elaborate a bit more on this point.

As the Merton prize is supposed to recognize the "best" illustration of analytical sociology, authors must have some ideas on what analytical sociology is in order to decide to compete for the prize. They may be wrong, but it seems fair to suppose that, when they submit their paper, they self-assess their work as potentially relevant for the analytical sociology program. The members of the prize committees are in a similar position. They may have different perceptions of what analytical sociology is or should be, but it seems fair to assume again that they are guided by these perceptions when determining whether a paper is a good illustration of analytical sociology. Thus, the interest of these papers is that they allow us to see what analytical sociology is at the intersection of submitters' and evaluators' subjective understanding of analytical sociology. Should we find that at the intersection of these two sets of subjective perceptions the Merton award winning papers stably follow a similar set of principles, we may conclude that analytical sociology, at least within the network of prize candidates and evaluators, has a core. Should this core be in line with the principles discussed by analytical sociology's manifestos, we may further conclude that analytical sociology practices what it preaches.

Thus, in what follows, I will use this set of papers inductively and, by using as a benchmark the seven postulates I employed above to express synthetically analytical sociology's principles and methods, I assess how these principles and methods materialized in substantive works that their authors and various prize committees regarded as best illustrations of analytical sociology. In particular, after describing some formal signs of the article's academic visibility (section 2), I investigate the following aspects: (1) the presence in the Merton awarded articles

4 The decision of naming the prize in honor of Robert King Merton wanted to signal the role played by Merton in the development of analytical sociology, both in terms of theorizing style and iconic models of social mechanisms (for a synthesis, see Hedström and Udehn 2009). A simple setup was designed for the prize. Both self-submission and third-party nomination were accepted; articles must have been published within the two academic years preceding the prize year; jury members were volunteers chosen among participants to the INAS annual meetings (or suggested by them); in 2016, the rule was introduced that the prize winner was an ex-officio member of the next year's prize committee; the prize committee had to work independently from INAS's council; honorable mentions were possible; the prize's call for submissions is usually advertised at the same time as the INAS annual conference's call for abstracts. 
Table I.1 Published journal articles having received the Merton award (or an honorable mention for it) by the International Network of Analytical Sociology between 2013 and 2020. For each paper, the following elements are shown: Prize committee composition, current number of citations, other academic prizes received, number of occurrences of the terms "analytical sociology" and "mechanism", and references to analytical sociology's manifestos

\begin{tabular}{|c|c|c|c|c|c|c|}
\hline Prize Year & Winners & Citations & Other Prizes & \#AS & AS Manifestos & \#Mechanism \\
\hline \multicolumn{7}{|c|}{ Prize Committee: Amir Goldberg, Andreas Flache, Daniel Alexandrov, Marc Keuschnigg (chair) } \\
\hline 2020 (a) & van de Rijt (2019) & 8 & - & 0 & - & 6 \\
\hline $2020(\mathrm{~m})$ & $\begin{array}{l}\text { Leszczensky and } \\
\text { Pink (2019) }\end{array}$ & 16 & - & 0 & - & 39 \\
\hline \multicolumn{7}{|c|}{ Prize Committee: Ozan Aksoy, Arnout van de Rijt (Chair), Elizabeth Roberto, Thomas Grund } \\
\hline 2019 & $\begin{array}{l}\text { Goldberg and Stein } \\
\text { (2018) }\end{array}$ & 39 & - & 0 & - & 19 \\
\hline \multicolumn{7}{|c|}{ Prize Committee: Gunn Birkelund, Marc Keuschnigg, Gianluca Manzo (chair), Christian Stieglich } \\
\hline 2018 & $\begin{array}{l}\text { Aksoy and } \\
\text { Gambetta (2016) }\end{array}$ & 16 & - & 0 & - & 0 \\
\hline \multicolumn{7}{|c|}{ Prize Committee: Sarah Cowan, Delia Baldassarri, Rense Corten (chair) } \\
\hline 2017 & $\begin{array}{l}\text { Keuschnigg and } \\
\text { Wolbring (2015) }\end{array}$ & 55 & $1^{5}$ & 0 & - & 12 \\
\hline \multicolumn{7}{|c|}{ Prize Committee: Emily Erikson, Tim Müller, Christoph Stadtfeld (chair) } \\
\hline 2016 & Cowen (2014) & 59 & $1^{4}$ & 0 & - & 5 \\
\hline \multicolumn{7}{|c|}{ Prize Committee: Amir Goldberg, Clemens Kroneberg (chair), Paolo Parigi } \\
\hline 2015 (a) & Bruch (2014) & 57 & $1^{3}$ & 0 & - & 10 \\
\hline $2015(\mathrm{~m})$ & Skvoretz (2013) & 47 & - & 1 & $\begin{array}{c}\text { H\&S (1996, } \\
\text { 1998); H(2005) }\end{array}$ & 88 \\
\hline \multicolumn{7}{|c|}{ Prize Committee: Guillermina Jasso, Thomas Grund (chair), Arnout van de Rijt } \\
\hline 2014 & Polavieja (2012) & 41 & $1^{2}$ & 0 & - & 6 \\
\hline \multicolumn{7}{|c|}{ Prize Committee: Elizabeth Bruch, Christopher Edling, Henning Hillmann (chair) } \\
\hline 2013 (a) & $\begin{array}{l}\text { DiMaggio and } \\
\text { Garip (2011) }\end{array}$ & 124 & & 0 & $\mathrm{H}(2005)$ & 30 \\
\hline $2013(\mathrm{~m})$ & $\begin{array}{l}\text { Kroneberg and } \\
\text { Wimmer (2012) }\end{array}$ & 55 & $3^{1}$ & 1 & $\mathrm{H} \& \mathrm{~B}(2009)$ & 19 \\
\hline
\end{tabular}

Notes:

$\mathrm{a}=$ prize winner; $\mathrm{m}=$ honorable mention

${ }^{1}$ European Academy of Sociology Publication Prize (2013); ASA Rationality and Society Section Best Article

Award (2013); Model Building and Simulation section Anatol Rapoport Award (2012).

${ }^{2}$ European Academy of Sociology Publication Prize (2013).

${ }^{3}$ Mathematical Sociology Section Outstanding Article Award (2015).

${ }^{4}$ Communication, Information Technologies and Media Section Best Paper (honorable mention) (2016).

${ }^{5}$ Model Building and Simulation section Anatol Rapoport Award (2014). 
of explicit references to analytical sociology and to the concept of mechanism (section 3); (2) the explananda of the Merton awarded articles and their scientific goal (section 4); (3) the way the Merton awarded articles design their explanatory machinery (section 5); (4) the way the Merton awarded articles combined data and methods to prove the empirical plausibility of the proposed mechanisms (section 6); (5) the presence in the Merton awarded articles' explanatory machinery of rational choice theories (section 7.1), and/or of "anomalous" theoretical elements (section 7.2).

\section{MERTON AWARDS' SIGNS OF VISIBILITY}

Before looking into the Merton awarded articles' content, let me first describe three formal indicators of the articles' academic visibility; namely, where they were published, the amount of citations they obtained, and their capacity to get other academic prizes.

As to publication outlets, one remarks that all the articles were published in highly visible and selective US-based or European journals. In particular, the eight prize winners appeared in American Journal of Sociology (4), American Sociological Review (1), Sociological Science (1), Rationality and Society (1), and the European Sociological Review (1). The three honorable mentions follow the same pattern: they were published in American Journal of Sociology (2) and in American Sociological Review (1).

As to citations, all the Merton awarded articles have already received some visibility on the citation market (see Table I.1). On average, until 30 November 2020, they received 47 citations (Google counts). With 124 citations, DiMaggio and Garip (2011), the "oldest" winner, is an outlier; with less than 20 citations, Aksoy and Gambetta (2016) and the two most recently awarded papers, both published in 2019 , are the least quoted; the seven other papers are close to the average number of citations. Again, honorable mentions do not differ systematically from their winner companions - while Kroneberg and Wimmer (2012) is less quoted than DiMaggio and Garip (2011), Leszczensky and Pink (2019) is more quoted than van de Rijt (2019), and Skvoretz (2013) is relatively close to Bruch (2014). These figures should not be used to draw inferences on the relative quality, or impact, of each single paper. They are simply intended to substantiate the general observation that none of the Merton awarded articles went entirely unnoticed compared to the vast majority of journal articles that are published each year without ever being quoted, or only getting a few citations (for this regularity, across fields and times, see for instance, Van Noorden et al., 2014: 551; Kim et al., 2020: Table 1).

Finally, as to recognition from outside the International Network of Analytical Sociology, Table I. 1 shows that five out of the eleven Merton awarded articles were awarded best article prizes by national professional associations (namely, the American Sociological Association and the German Sociological Association) and international science academies (namely, the European Academy of Sociology). Again, when comparing Merton honorable mentions with Merton prize winners, no systematic variation seems to exist: in one case, none of the two papers received another prize; in one case, the winner did, but not an honorable mention; and, in a third case, the symmetric situation occurred.

Thus, overall, the works finally recognized by the Merton prize committees as illustrating analytical sociology at its best cumulated a certain number of formal signs of academic visibility: they were all published in highly visible, mainly generalist, academic journals; they had already got some visibility on the citation market; and, for about half of them, they 
were also prized by academic instances other than the International Network of Analytical Sociology. 5

\section{MERTON AWARDS' FRAMING CHOICES}

To move progressively from external signs of academic visibility to the articles' content, a preliminarily important question that should be addressed concerns the extent to which the Merton awarded articles explicitly embedded their substantive investigations within the metatheoretical frames of analytical sociology and mechanism-based explanations.

Let me first consider the programmatic reference to "analytical sociology". Table I.1 (column "\#AS") shows the number of occurrences of this expression in each article's abstract, main text, and footnotes. Surprisingly enough, it appears that the label "analytical sociology" is virtually absent from the Merton awarded articles. Only two of them employed it explicitly. In particular, Kroneberg and Wimmer (2012: 181) referred to analytical sociology when they explicated how their account of the formation of political alliances differed from existing macrostructural approaches, and claimed: "By contrast, our formal model follows the program of an analytical sociology (Hedström and Bearman 2009) and fully specifies all key mechanisms and assumptions". As to Skvoretz (2013: 486), the term appeared only generically in the article's abstract, where it stated that "In the spirit of analytical sociology, the author explores two mechanisms that could drive intra- and intergroup relations: attraction to similar versus repulsion from dissimilar others."

Table I.1 (column "AS manifestos") also shows that the virtual absence of the label "analytical sociology" from the Merton awarded articles translated into the scarcity of explicit references to the articles and books that attempted to progressively codify analytical sociology's principles and methods (see sections 1.1 and 1.3 above). Apart from Kroneberg and Wimmer (2012: 181) who explicitly quote Hedström and Bearman (2009) once, only DiMaggio and Garip (2011: 1888) quoted Hedström (2005) once; and Skvoretz (2013: 486) quoted Hedström and Swedberg (1998) and Hedström (2005) once. Leszczensky and Pink (2019: 396-7) may be considered a limit case in that they framed their use of stochastic actor-oriented modeling for longitudinal network data as "adding to the larger agenda of how social interactions among individuals result in aggregate outcomes" and quoted, for this agenda, Hedström and Manzo (2015)'s note on agent-based modeling as well as Keuschnigg et al.'s (2018) analysis of the relationships between analytical sociology and computational social sciences. References to substantive works from authors of analytical sociology's manifestos are not frequent either. These are limited to Hedström's earlier papers on spatial diffusion (see van de Rijt 2019: 1487), Hedström's chapter on rational imitation (see Polavieja 2012: 603; van de Rijt 2019: 1483, 1486), and Manzo and Baldassarri's (2015) study of the emergence of status hierarchies (see van de Rijt 2019: 1469-70).

\footnotetext{
Let me emphasize that I am considering these three features from a purely descriptive point of view. My question here is only: do the articles that finally won the Merton prize possess some sign of academic visibility? From the answer to this question, which happened to be positive, I do not want to infer any causal effect on whether or not following analytical sociology's principles increases the chance of getting published in top journals, of being quoted, and/or of receiving a variety of academic prizes.
} 


\section{Research handbook on analytical sociology}

However, it should be noted that, if explicit references to the analytical sociology's manifestos I discussed in section 1 are virtually absent from the Merton awarded articles, all of them contain at least one reference to concepts, models, and/or specific mechanisms that those manifestos have recurrently considered as part of the fundamental toolbox of analytical sociology. In particular, these are: (a) Schelling's iconic residential segregation model (see Bruch 2014: 1227; DiMaggio and Garip 2011: 1894) and his book Micromotives and Macrobehaviours (see Bruch 2014: 1227); (b) Coleman's contribution to mathematical sociology (see Skvoretz 2013: 492), analysis of the micro/macro loop (see Polavieja 2012: 602,622 ), conceptualization of social capital (see Keuschnigg and Wolbring 2015: 102), as well as his creative analyses of diffusion through networks (see DiMaggio and Garip 2011: 1894; Cowen 2014: 468); (c) Merton's analysis of homophily (see DiMaggio and Garip 2011: 1892; Leszczensky and Pink 2019: 397) and of cumulative advantage mechanisms (see van de Rijt 2019: 1469); (d) White's model of vacancy chains (DiMaggio and Garip 2011: 1889); (e) Granovetter's theory of weak ties (see DiMaggio and Garip 2011: 1894; Keuschnigg and Wolbring 2015: 102) and threshold models (see DiMaggio and Garip 2011: 1894; Goldberg and Stein 2018: 900; van de Rijt 2019: 1469); (f) Boudon's analysis of educational inequalities (DiMaggio and Garip 2011: 1889), of generative versus statistical models (see Skvoretz 2013: 488), and of rational action (see Polavieja 2012: 622); (g) Elster's studies of norms (see Polavieja 2012: 602) and rational self-commitment (Aksoy and Gambetta 2016: 793) as well as Elster's treatise on Nuts and Bolts (see van de Rijt 2019: 1470). The recurrence of this set of analytical sociology's relevant references throughout the Merton awarded articles clearly conveys a sense of family resemblance across the articles.

Let me now consider the use of the basic meta-theoretical building-block of analytical sociology, i.e. the concept of mechanism. As shown in Table I.1 (column "\#Mechanism"), with one exception, all Merton awarded articles explicitly and repeatedly employed the term "mechanism" to refer to their explanatory machinery. This is indeed the linguistic element that really generates a sense of unity across the Merton awarded articles. However, variation around the average number of occurrences (21) is substantial, and marked differences in the level of explicitness of the definition of the concept of mechanism appear across the articles.

In particular, on the one hand, the reader finds DiMaggio and Garip (2011: 1888), who explicitly endorsed a definition of a "social mechanism" as entailing (a) goal-directed individual actions and (b) consequent social interactions that (c) yield higher-level outcomes that (i) are emergent (i.e. that cannot be recovered simply by aggregating individual actions that combine to produce them) and (ii) vary depending on the initial social structure (ordinarily depicted in terms of social networks). For this understanding of a mechanism, they referred to Hedström (2005), and, interestingly, to Tilly's book on Identities, Boundaries, and Social Ties. Similarly, Skvoretz (2013: 486) explicitly quoted the definition proposed by Hedström (2005: 11 ), according to which a social mechanism can be generically understood as "a constellation of entities and activities that are organized such that they regularly bring about a particular type of outcome". On the other hand, the reader finds Aksoy and Gambetta (2016) who did not even use the term "mechanism," even though, as we will see in section 5, the theoretical hypotheses they wanted to test empirically were explicitly, and transparently, formulated in terms of actors' preferences, their potential strategic choices, and their reactions to proximate (namely, the neighborhood an actor lives) and distant (namely, norm and value macro-changes) social contexts. The remaining Merton awarded articles, hence the majority of them, fall between these two extreme cases. They recurrently employed the term "mechanism" without 
explicitly defining it. However, as I will show in section 5, this did not translate into a rhetoric use of the concept of mechanism. Each article in fact described a well-described chain of events unfolding at different scales, these events being fuelled by the actions and interactions of equally well-specified entities who follow clearly identified logic, and this under overtly explicated scope conditions (for a summary, see Table I.2's columns "Explanans"). In this sense, no matter whether explicitly defining the term or not, all the Merton awarded articles employed the concept of mechanism in agreement with analytical sociology's manifestos, which progressively converged toward generically seeing a mechanism as a set of organized entities whose properties and activities are able to trigger changes that generate the observed connections with some regularity (see Hedström 2005: 25; Manzo 2010: 138; Manzo 2014: 14; Keuschnigg et al. 2018: 5).

Thus, overall, the works finally considered by the Merton prize committees as illustrating analytical sociology at its best shared a paradox: the majority did not explicitly refer to analytical sociology's manifestos to frame their substantive investigations and, while they employed the term "mechanism" widely, they did not define the term explicitly. It is the use of secondary references (i.e. references to concepts, models, and typical mechanisms that analytical sociology's manifestos recurrently regarded as founding pieces of the analytical sociology's toolbox) as well as the way concrete mechanisms are designed that gave the Merton awarded articles a sense of unity and of family resemblance. One must, then, carefully inspect the inner working mode of these articles to assess the extent to which they illustrated the principles and the methods of analytical sociology. ${ }^{6}$

This is what I do in the next four sections, where I inspect Merton awarded articles' explananda (section 4), the structure and the content of their explanans (section 5), the way the explanans is connected to the explanandum through data and methods (section 6), and what type of action and structural theories are mobilized (section 7).

\section{MERTON AWARDS' EXPLANANDA}

Analytical sociology's manifestos have repeatedly presented analytical sociology as primarily concerned with the explanation of puzzling "collective properties" (see Hedström 2005: 67) or "social facts" (Hedström and Bearman 2009: 3). As we have seen in section 1, the first two postulates of the analytical sociology's core research strategy as synthetically defined by Manzo (2014: 7) are all about the preliminary conceptual and the empirical identification of these facts. Manzo (2014: 9, 38) even characterized the overall intellectual project of analytical sociology as "an empirically oriented, experimentally and computationally based, macro-sociology with clearly explicated and empirically grounded dynamic micro- and

\footnotetext{
$6 \quad$ It seems very difficult to ascertain empirically the mix of motives behind the choice of not referring explicitly and extensively to analytical sociology's manifestos. It may be that authors want to save space for substantive analyses and methodological developments rather than discussing research principles on a meta-theoretical level; it may also be that authors expect reviewers of certain journals to dislike this type of programmatic discussion. Authors may also act strategically. Depending on how they perceive the academic reputation of analytical sociology, they may consider that explicitly mentioning analytical sociology may reduce, rather than increase, the chance their substantive analyses are objectively assessed; they may also associate analytical sociology with specific authors to whom they may not want to give credit. I will not pursue these speculations here. The important point is to highlight the paradox. As I will argue in the concluding section, being aware of it is the first step to appreciate its potential negative consequences.
} 


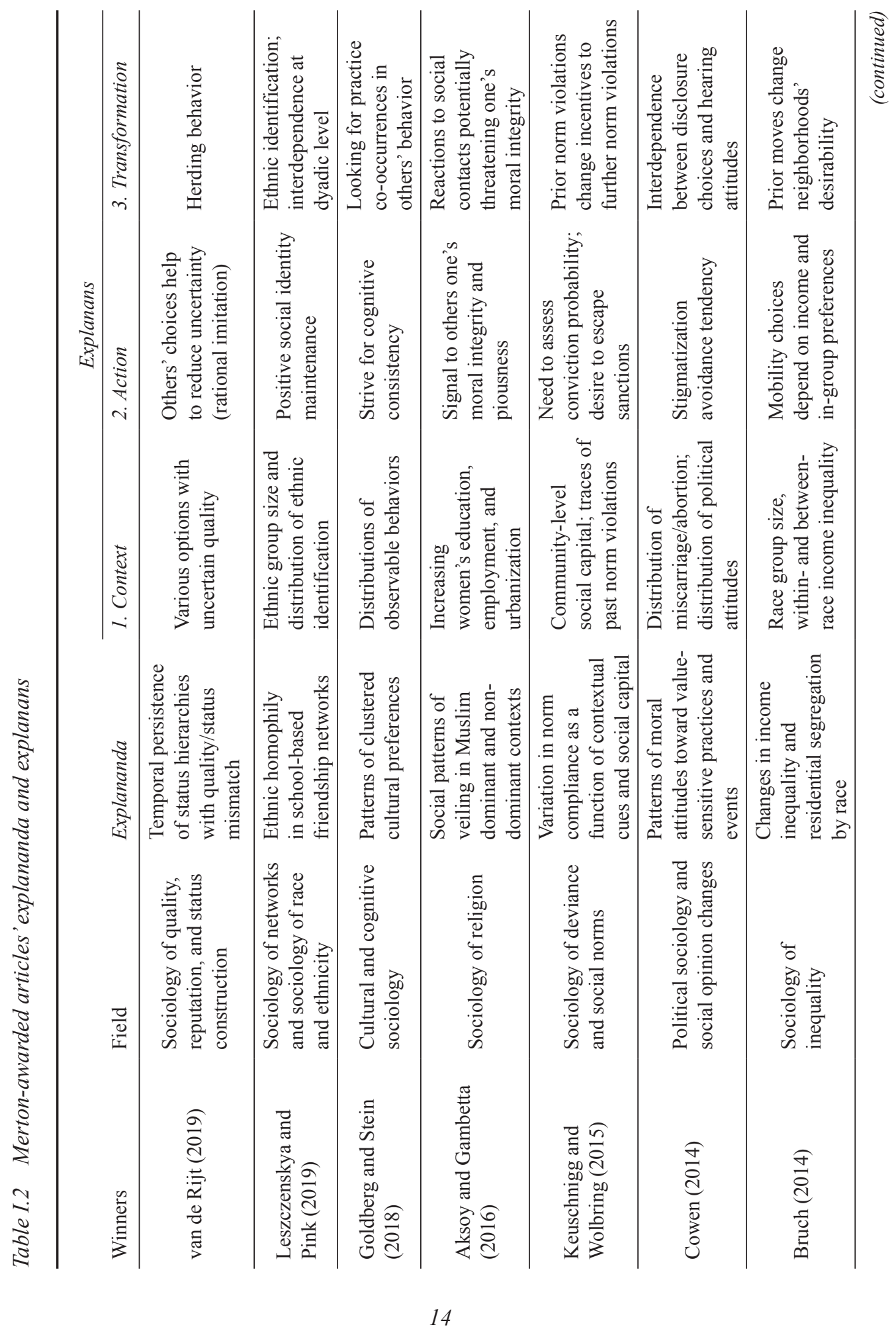




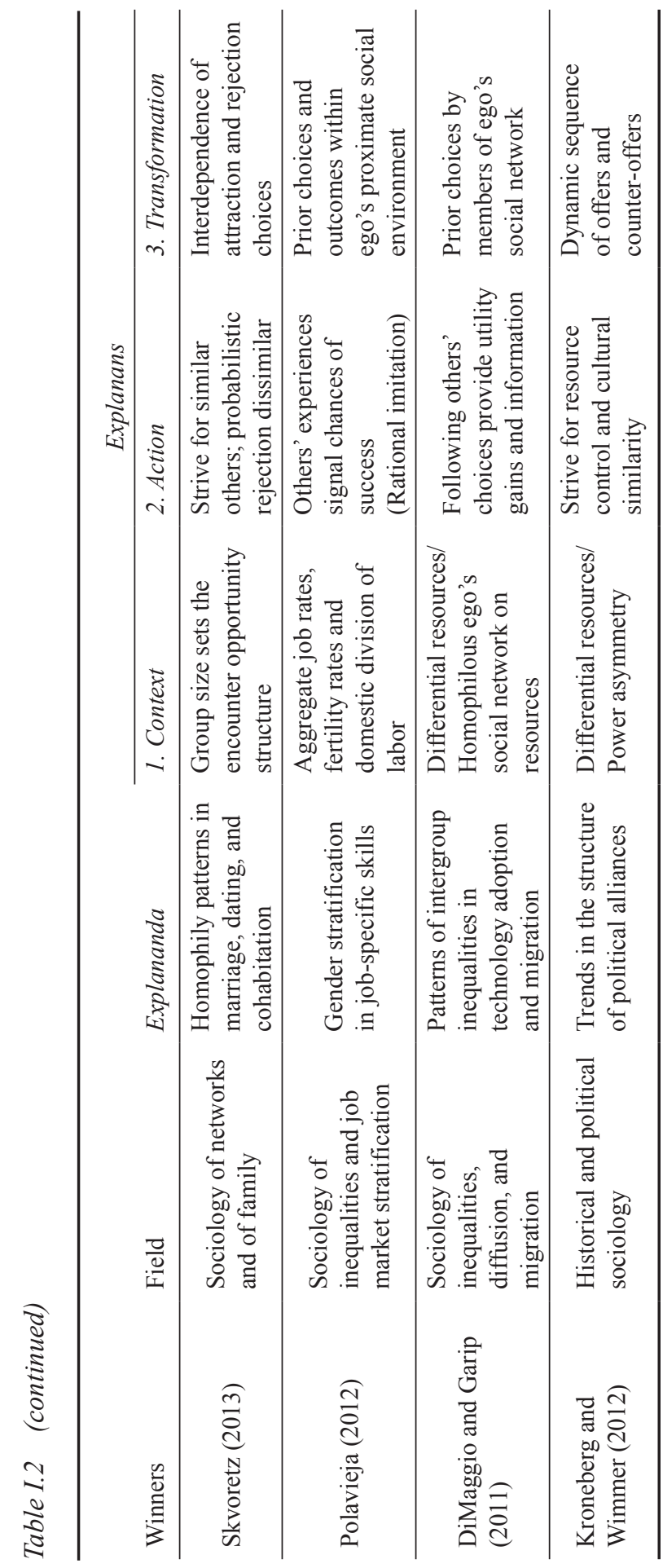


network-level foundations". As a minimal, working definition of what "collective properties" or "social facts" are, analytical sociology progressively converged to consider "macro", what cannot be defined, measured, or understood with reference to a single member of the population of interest (Ylikoski 2012: sec. 2.3). For this reason, phenomena of interest of analytical sociology, and more generally of scholars interested in mechanism-based explanations, have also been generically defined as structural properties (see Marchionni and Ylikoski 2013: 334).

Table I.2 (column "Explananda") synthetically shows that each Merton awarded article focused on a well-identified "structural property" with the explicit goal of explaining its emergence and/or temporal stability/instability. These "structural properties" touched upon a large spectrum of macro phenomena, and spanned across a variety of specialized sociological fields (see Table I.2, column "Field").

In particular, DiMaggio and Garip (2011: 1899, 1916) contributed to sociology of inequalities, of the diffusion of innovations, and of migration by studying the persistency over time of intergroup inequality in at-home internet use in the US between 1997 and 2007 and, on the other hand, the variation over time of rates of intergroup rural-urban migrations among 22 rural villages in Thailand between 1972 and 2000. Kroneberg and Wimmer (2012: 177, 198, 220-1) wanted to explain macroscopic patterns of historical political changes "[...] from the estate model of society under the ancien régime, through populism, to fully inclusive nation building", with a particular focus on France (1300-1900) and the Ottoman Empire (1500-1900), thus contributing to comparative historical sociology of nation-state formation and political sociology. Polavieja (2012: 594, 620) aimed at understanding gender-based patterns of investments in job-specific skills in 234 different regions of 24 European different countries, thus contributing to the field of sociology of inequalities and job market stratification. Skvoretz (2013: 489) wanted to explain variations in levels of homophily by nationality, ethnicity, race, education and religion in marriage, dating, and cohabitation as observed in many societies, including the United States, Great Britain, Austria, and 21 other European nations, thus contributing to sociology of networks and couple formation.

Bruch (2014: 1223-4, 1246) contributed to stratification research by studying the temporal interdependence between the size of race groups, in particular white and blacks, the levels of income inequality within and between those groups, and the resulting patterns of racial residential segregation in major American cities, including Los Angeles, Atlanta, and Chicago, between 1980 and 2000. Cowen (2014: 466) contributed to the sociology of political opinion and social change by analyzing the connection between patterns of hearing and disclosure of private information on emotionally and value-loaded women's subjective life events, like miscarriage and abortion, and the persistence of liberal/conservative attitudes toward these events among contemporary American adults. Keuschnigg and Wolbring (2015: 97, 98, 103) wanted to understand spatial variations in the compliance to social rules for low-cost behaviors (like littering, jaywalking, or stealing small amounts of lost money) as a function of contextspecific cues (of existing levels of norm violation) and varying amounts of neighborhood-level social capital, thus contributing to sociology of deviant behaviors and social norms. Aksoy and Gambetta (2016: 372) aimed at understanding social patterns of Muslim women's propensity to veil (in Belgium, Turkey, and 25 other Muslim countries) as a function of those women's socio-economics attributes, levels of religiosity, and the type of neighborhood they leave in, thus contributing to sociology of modernization and religion as well as to political sociology. Goldberg and Stein's $(2018: 897,903,908)$ study fell within the field of cultural and cognitive sociology: they wanted to understand how individuals progressively come to associate 
specific subjective meanings to given cultural practices and how, once these meanings are in place, cultural practices are endorsed as clusters of practices rather than isolated practices, thus making cultural differentiation a cognitively embedded macro phenomenon. Leszczensky and Pink (2019: 394, 397) studied levels and temporal variations of segregation by ethnic groups in friendship networks at school among German young adolescents as a function of students' ethnic identification, thus contributing to sociology of social networks and ethnicity. Finally, van de Rijt (2019: 1469-70, 1472) contributed to sociology of quality, reputation, and status construction by explaining the potential temporal instability of status hierarchies where inferior options initially outperform superior ones as a function of the strength of the social influence affecting the individuals who have to choose these various options.

Thus, the Merton awarded articles well illustrated the $a$-specific nature of analytical sociology. Topics of interest of analytical sociology are not defined a priori. Analytical sociology is a generic sociological perspective: it is not tied to a specific substantive field. Explananda can be of any kind provided they concern "structural properties", i.e. cross-sectional and/or dynamic patterns of behaviors, practices, or outcomes across socio-economics/demographic groups, and/or social contexts that cannot be understood, measured, and explained by reference to any single member of the population under exam.

The Merton awarded articles nicely showed that these structural properties can be points of equilibrium of a social system-like cultural differentiation in Goldberg and Stein (2018) - transitions from one equilibrium to another-like historical changes in political regime modelled by Kroneberg and Wimmer (2012) or unstable status hierarchies analyzed by van de Rijt (2019) — or still dynamic flows — like migrations in DiMaggio and Garip (2011). Structural properties of interest can also be associations between contextual features at one point in time and distributions of attributes or choices at a subsequent point in time-like the dependence of gender-based investments in job-specific skills on gender-based occupation rates studied by Polavieja (2012), the impact of contextual cues and level of social capital on deviant behaviors analyzed by Keuschnigg and Wolbring (2015), or levels of modernization and variation in religious behaviors inspected by Aksoy and Gambetta (2016). Structural properties can also be associations between population distributions - like the association between income distribution and residential segregation studied by Bruch (2014) or the dependence of the distribution of political opinions and that of value-loaded practices and events analyzed by Cowen (2014). In some cases, structural properties of interest concerned the configuration of social ties, without further moving on to a higher level of abstraction-like the various forms of network homophily studied by Skvoretz (2013) and by Leszczensky and Pink (2019).

No matter the specific content and form of the structural properties of interest, all Merton awarded articles clearly formulated the explanandum in a transparent and pedagogical way, typically in the article's introductory section. The description of the explanandum is always associated to a why-question: the main goal is to understand the source of the structural properties of interest. Sometimes, the why question is formulated in terms of "puzzles", i.e. an intriguing fact that arises from the contradiction between theoretical expectations and empirical observations, or an unexpected contradiction between facts themselves (see, for instance, DiMaggio and Garip 2011: 1988, 1895, 1913, 1914; Kroneberg and Wimmer 2012: 179; Polavieja 2012: 592-3; Aksoy and Gambetta 2016: 792, 803; Goldberg and Stein 2018: 898). In all cases, the answer to the why-question takes the form of a how-solution: the bulk of each Merton awarded article consists in the formulation of a chain of events unfolding at different scales, these events being fueled by the actions and interactions of well-specified entities who 
follow clearly identified logics, i.e. a mechanism operating under overtly explicated specific conditions.

As we will see in the next section, while the specific content of this mechanism varies from one article to another, its structure is relatively stable. In particular, a common feature of each proposed mechanism is action interdependence. No Merton awarded article considered that the simple accumulation of individual actions unfolding independently from one another was sufficient to make the macroscopic outcome of interest transparent.

\section{MERTON AWARDS' EXPLANANS}

Analytical sociology's manifestos formulated various typologies of social mechanisms. In particular, Hedström and Swedberg (1996: 296-8; 1998: 22) initially followed the three main branches of the Coleman's diagram and proposed to distinguish between "situational", "action-formation", and "transformation" mechanisms. Hedström (2005: chapter 3) added specificity to this typology by formulating, on the one hand, a generic sub-typology of mechanisms involving dyadic interactions (ibid., 47-56) and, on the other hand, a list of typical action-formation mechanisms involving various patterns of opportunity-beliefs-desires connections (ibid., table 3.1).

The explicit use of these typologies of social mechanisms is virtually absent from the Merton awarded articles. Polavieja $(2012: 603,622)$ is the only exception: he directly relied on "rational imitation" (one of the action-formation mechanisms of Hedström's typology) and explicitly, though generically, referred to the concept of "situational mechanism". However, the explanations proposed by each Merton awarded article are fully in line with these typologies. Indeed these explanans systematically combined three aspects: (1) a description of the specific pathways through which the context in which actors shape their beliefs, preferences, and/or opportunities (i.e. situational mechanisms); (2) the principles underlying actors' actions (i.e. action-formation mechanisms); and (3) how action interdependency progressively generates the macro outcome of interest (i.e. transformation mechanisms). The three columns of Table I.2 under the common heading "Explanans" aim to help the reader synthetically appreciate these explanatory elements, thus facilitating cross-article comparisons. In what follows, I will try instead to restitute as neatly as I can the details of each proposed explanation. To do so, I will consistently use 1, 2, and 3 to refer to elements related to situational, action-formation, and transformation mechanisms, respectively. When more than one elements substantiate a given mechanism, I will adopt multilevel lists (for instance, $1.1,1.2(\ldots), 2.1,2.2$, and so on). ${ }^{7}$

Let me start with Kroneberg and Wimmer (2012: 177, 187-9), who wanted to explain how political modernization can lead to a national community, to a set of segmented ethnic groups, or to populism. To do so, they framed the problem in terms of typical political alliances that are more likely to emerge. The proposed mechanism driving the formation of these alliances is organized as follows: (1) actors (collective actors, in this case) have different resources (as captured by taxing capabilities and provision of public goods), different power (as captured by military resources), different cultural identities (as captured by religion, language, skin

7 I thank Viviana Amati for this suggestion and for noting symbol inconsistency in a previous version of the text. 
color, and various cultural dispositions) as well as different distance from the center of the political decision making; (2) giving this resource distribution and power asymmetry, to form their preferences for potential allies, the actors' goal is to find the best balance between control over resources and the ally's cultural proximity; (3) in this context and given these preferences, central elites make proposals, peripheral elites make counter-proposals, and masses decide who they want to support, thus creating a dynamic sequence of offers and counter-offers that will stabilize at some point when no actor can find a better ally. Kroneberg and Wimmer (2012: $177-8,208,215,2017)$ clearly identified the conditions under which the posited "struggle" is more likely to end with a given alliance system - the stronger the state and the denser the network of civil society organizations, the higher the probability that inclusive and consensual alliances and identities will emerge.

DiMaggio and Garip (2011: 1888-9, 1893, 1900) wanted to explain the generation of inequalities in internet adoption among individuals with different incomes and education, as well as over-time divergent rural-urban migration rates between Thai villages. To do so, they proposed a common mechanism made of the following elements: (1.1) actors possess different amount of resources to sustain the costs of subscribing internet or to migrate; (1.2) actors experience proximate social networks that tend to be homophilous with respect to socio-economic factors; (2) when making up their mind about whether to adopt or migrate, actors look at prior adoption choices among their relevant direct contacts (i.e. friends or family members) - because having friends using the Internet increases the benefits of having it, and having migrant friends or family members provide information and logistic help to migrate (ibid., table 1); (3) relying on choices of proximate others with similar amount of resources will amplify non-adoption among have-nots and adoption among haves. DiMaggio and Garip (2011: 1888, 1891) clearly stated the condition under which the posited mechanism is likely to generate intergroup inequality: network homophily must exist on factors that are associated with adoption.

To explain the underrepresentation of women in highly specialized jobs, Polavieja (2012: 592-3, 600, 603) proposed the following mechanism: (1.1) actors' proximate social environment is rich in cues informing them about their job survival risks in different investment paths; (1.2) in particular, actors can look into previous generation's outcomes, domestic labor division in peers' couples, and peers' fertility behaviors; (2) actors rely on others' past and contemporary experiences to roughly estimate their survival probability in a given job; (3) by looking at others' past and contemporary experiences, actors who are surrounded by proximate social environment with less favorable signals about their chances of success in jobs requiring specific skills will be discouraged to follow this paths on the job market. Polavieja (2012: 594) posited that this mechanism is more like to operate for groups like women that face greater uncertainty and higher risks when assessing different job market options.

Skvoretz (2013: 491-3, 499) wanted to explain the variations of homophily on various attributes in different types of couple formation relationships and, to this aim, he proposed a mechanism involving the following elements: (1) the demographic size of groups provide actors with certain opportunities for encountering similar and dissimilar others; (2) actors' are driven by a tendency toward homophily so that their preference for similar others bias the structural constraints; in particular (2.1) when someone meets a similar individual, then the tie is always formed (attraction mechanism); otherwise, (2.2) when someone meets a dissimilar other, the tie is rejected with a given probability (repulsion mechanism); (3) one's attraction/rejection choices dynamically change the opportunity to encounter structures for 
subsequent attraction/rejection choices. Depending on the initial group size, and the intensity of the rejection bias, variations in the level of homophily along different attributes emerge in different settings. Skvoretz (2013: 500) identified the following scope condition: "repulsion is the driver of intergroup relations when the dimension type is ascribed, like ethnicity/race and religion, while attraction is the driver of intergroup relations when the dimension type is achieved, like educational attainment".

To explain the complex three-way interdependence between the distributions of income and race, and patterns of racial residential segregation, Bruch (2014: 1221-2, 1243-5) built the following mechanism: (1.1) actors belong to race groups with different sizes, possibly changing over time; (1.2) they also have income that is variable both between race groups and within them, and possibly changing over time; (2) actors move from one neighborhood to another as a function (among other factors) of their income and the race composition of the potential new destination, with relatively mild in-group preferences; (3) each family's residential move changes the race composition of neighborhood for subsequent choices. When income and race are correlated, the dynamic interplay of sequential moves generates offsetting effects where affluent blacks may experience larger exposure to affluent white neighbors whereas poor blacks may find themselves even more intensely isolated within low-income black neighborhoods. Bruch $(2014$ : 1224, 1263, 1264) identified the conditions under which offsetting is more likely to happen - namely sufficiently high within-race income inequality, increasing between-race income inequality, and sufficiently high proportion of blacks - and clarified that "whether these offsetting processes result in a net increase or decrease in segregation depends on the relative size of the black population, the salience of racial versus economic factors in residential mobility decisions, and the shape of the income distribution" (ibid., 1224).

To explain how patterns of secret hearing and disclosure impact population-level opinion changes, Cowen (2014: 471-2) described the following mechanism: (1.1) at any given time, a stock of private events (miscarriage and abortion, here) exists in the population; (1.2) women personally experiencing these events may decide to share their experience to relevant confidants like friends, family members, colleagues, or more distant acquaintances; (2) when disclosing secrets, actors want to avoid stigmatization; (3) as a consequence, private events that are less likely to be disapproved (miscarriage rather than abortion) will be more frequently disclosed, and they will be more frequently disclosed to those confidants that are perceived as having more favorable views on the to-be-disclosed event (namely, those with liberal rather than conservative political attitudes). The dynamic interdependence between disclosure choices and hearing attitudes is likely to create what Cowen (2014: 495) calls a "self-fulfilling illusion"-more stigmatized events will be less present in actors' subjective perceptions than they actually are in the population, and those who are more likely to disapprove the events will be less likely to be aware of them-which is likely to slow down attitude changes. As a by-product, Cowen's (2014: 484) mechanism identified awareness of others' behavior as a necessary condition for social influence: "Selective disclosure and secret keeping [...] are mechanisms for thwarting social influence by preventing the awareness that is a precondition of influence [...]".

To explain variations in levels of norm compliance across local settings, Keuschnigg and Wolbring (2015) designed the following mechanism: (1.1) actors live in local context with varying levels of others' supportiveness, quality of social relationships, and shared activities 
(i.e. "social capital"); (1.2) social environment also contains varying amount of traces (like physical or social disorder) of previous norm violations; (2) when making up their mind about whether to comply with a norm, actors exploit contextual cues as an heuristic to infer the probability of being sanctioned; (3) looking at previous violations of a given norms (litter, for instance) can lead actors to further violation of the same norm ("same-norm inhibition effect"), and also to feel more comfortable with violating other norms ("cross-norm inhibition effect"); for instance, by stealing a small amount of in-the-street lost money after seeing littering. Depending on the initial stock of violations displayed in a given local context and the amount of social capital, temporal interdependence between norm violation choices will lead to varying levels of norm compliance. Keuschnigg and Wolbring (2015: 99) clearly formulated a scope condition for the mechanism: the smaller the norm to be violated (i.e. a norm associated with minor sanctions), the more the actors rely on contextual signals rather than on lengthy cost-benefit evaluations. Reasoning that past norm violations within a civic environment are likely to be more informative than within those that are structurally disordered, Keuschnigg and Wolbring (2015: 103) also identified a moderating condition for the mechanism: the effects of contextual signaling are likely to be stronger when social capital is high.

To explain variations of veiling behaviors among Muslim women in Muslim dominant and non-dominant contexts and, in particular, the possible counter-intuitive positive correlation between modernization and veiling frequency, Aksoy and Gambetta $(2016: 793,796)$ posited the following mechanism: (1) modernization leads Muslim women to experience more education, greater access to job market, and to urban settings; (2.1) Muslim women may veil because they believe this is a religious requirement; but (2.2) they may also veil to signal their moral integrity to members of their home community as well as to new social contacts outside this community. If so, (3.1) modernization, by making religious beliefs less prominent, may reduce veiling's average frequency while, (3.2) by exposing Muslim women to more secularized settings may increase the propensity of veiling among women who remain highly religious, and who are highly educated, urban, and middle class; (3.3) highly religious women living in urban neighborhoods where veiling is less frequent and more various in terms of dressing manifestations, as well as highly religious women who live in neighborhoods where Muslims are a minority, should also manifest a higher propensity to veil because these two types of neighbourhoods are likely to increase the necessity for women to signal their moral integrity and piousness.

To explain the emergence of clusters of cultural practices without assuming social network segmentation, Goldberg and Stein (2018: 908) developed the following mechanism: (1) actors have an initial set of perceptions about how strongly practices are associated to one another; (2.1) actors have initial preferences for a set of practices; (2.2) actors endorse and exhibit a given practice proportionally to the strength of the preference for that practice; (2.3) as co-occurrences of practices are observed, actors update their preferences for given practices as long as the practices at hand are compatible with the current state of their set of perceived associations among practices; (3) actors observe other actors' practices and, when they observe that two practices are endorsed by a given actor, they reinforce their own perceived association between the observed practices. Goldberg and Stein (2018: 906-7) called this mechanism "associative diffusion" and demonstrated that it is sufficient to generate agreement among agents on which practices go together while allowing agents to have different preferences for specific practices (ibid., 914). They also formulated the condition under which "associative 
diffusion" is more likely to apply, namely when behaviors are observable and when the utility of adopting a given practice is uncertain (ibid., 921-2).

To explain same-ethnic friendship, and thus ethnic segregation in friendship networks at school, Leszczensky and Pink (2019: 396-7, 399-401, 403) combined the following elements: (1) the size of ethnic groups structurally constrain the opportunity to form ties with students from a given ethnic background; (2) given these constraints, students' are sensitive to potential friends' ethnicity but they also try to preserve a positive social identity by not befriending someone with markedly different levels of ethnic identification; (3.1) when this goal is in place, high identifiers may prefer same-ethnic friends provided they are also high identifiers, while excluding low identifiers even though they may come from the same ethnic group; (3.2) symmetrically, low identifiers may avoid to befriend high identifiers irrespectively of their ethnicity; (3.3) preferential attachment, exclusion, and avoidance are expected to operate under dynamically evolving levels of ethnic identification, because adolescents may adjust their own level of ethnic identification to that of their friends.

Finally, to explain the potential instability of status hierarchies where low-quality options are more popular than high-quality ones, van de Rijt (2019: 1469-70, 1472) proposed the following mechanism: (1) in the actors' proximate social contexts, several options (goods, ideas, opinions, etc.) exist, and (1.2) some actors have already chosen one of these options; (2) to assess the option's quality, actors' are positively and monotonically (but probabilistically) sensitive to the proportion of people choosing a given option so that the higher that proportion, the stronger the preference for the option at hand; (3) under these conditions, the smaller the initial proportion of those choosing inferior options, the higher the chance that some individual deviates from this choice, thus progressively triggering a new majority leading to the correct evaluation of superior alternative. Van de Rijt $(2019: 1470,1486)$ identified the "magnitude of the social influence effect" as the main condition under which status can be decoupled by quality: unless this effect is unrealistically high, he claimed, a self-correcting dynamic will always have a sizeable chance to happen.

Thus, behind the variety of the specific content of each explanans, all Merton awarded articles followed a common logic to design this explanans: (1) they described how contexts shape actions; (2) they explained why actions are performed; and, (3) they described how action interdependence led to high-level patterns. In this sense, the Merton awarded articles all instantiated the third and fourth postulates of the analytical sociology's core research strategy as synthetically defined by Manzo (2014: 9) (see section 1.3). Moreover, in spite of the absence most of the time of an explicit definition of the concept of mechanism (as we have seen in section 3), and, as I have noted above, without directly referring to typologies of mechanisms proposed by analytical sociology's manifestos, the Merton awarded articles all provided a "mechanism" that fully meets the generic definition of a mechanism toward which those manifestos progressively agreed over the years, which see a mechanism as a set of organized entities whose properties and activities are able to trigger changes that generate the observed connections with some regularity (see Hedström 2005: 25; Manzo 2010: 138; Manzo 2014: 14; Keuschnigg et al. 2018: 5). Of particular interest is the fact that the conditions under which the proposed mechanism is expected to operate are always clearly formulated. This was one of the critiques addressed to early analytical sociology's manifestos: the lack of attention for scope and triggering conditions (see Gross 2009: 373; for a reply, see also Manzo 2010). The Merton awarded articles avoided this shortcoming. 


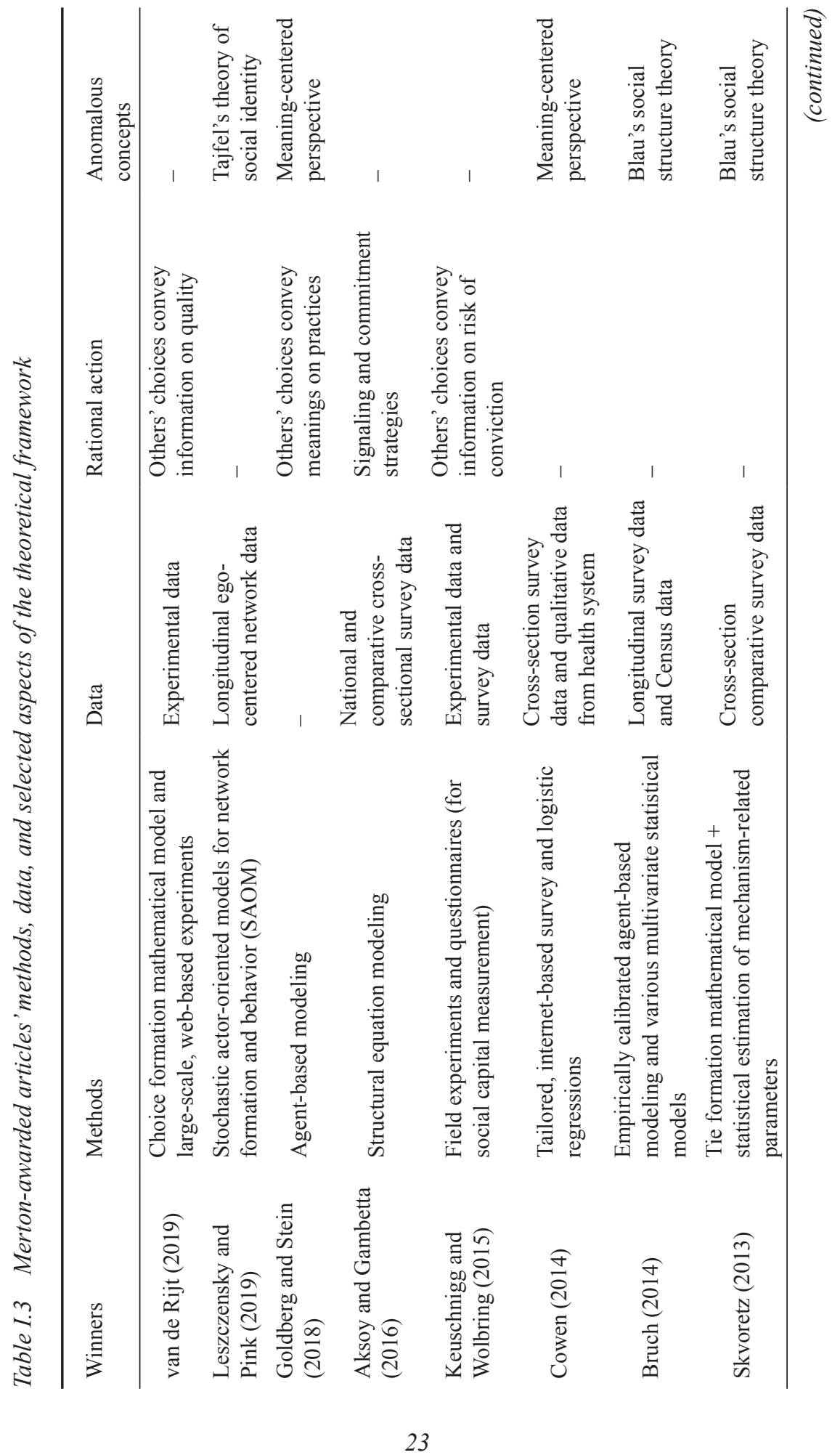




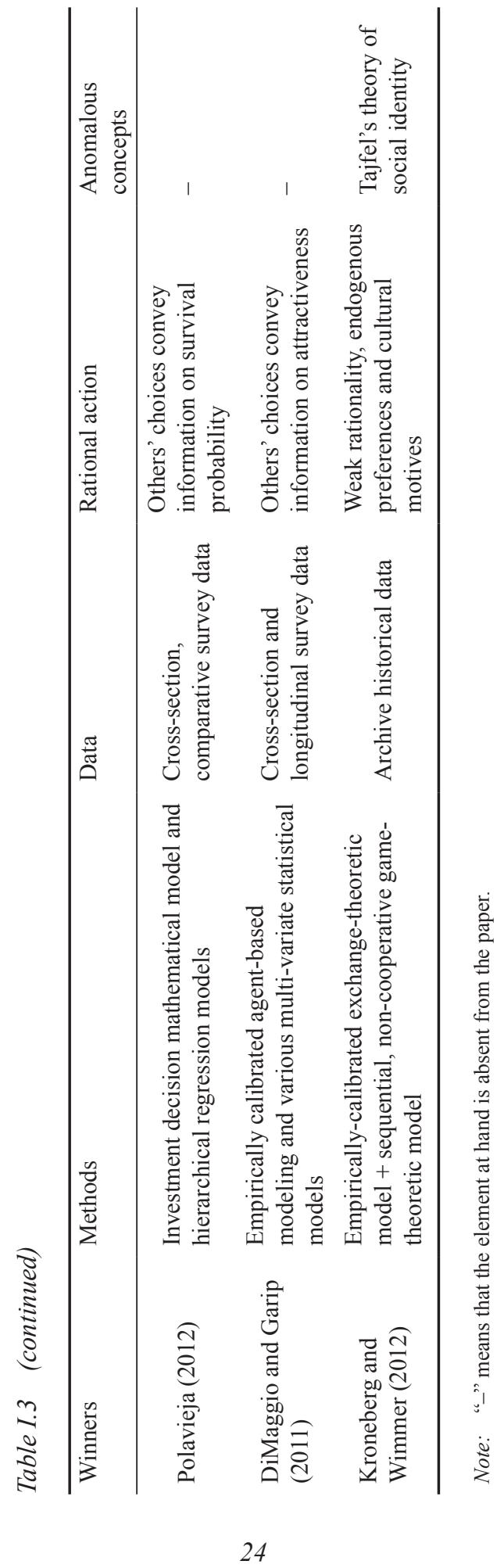




\section{MERTON AWARDS' DATA AND METHODS}

How did the Merton awarded articles combine data and methods to persuade the reader that the explanans, i.e. the postulated mechanisms that I reconstructed in the previous section, can be regarded as realistically at work in the real world?

In section 1 we saw that analytical sociology's manifestos set a progressively more precise and demanding methodological agenda for mechanism-oriented social research. The field started from a critique of the explanatory deficiencies of correlation-oriented multivariate statistics (see Hedström and Swedberg 1998: 15-17; Hedström 2005: chapter 5), moved on to an increasing emphasis on combining statistical methods with agent-based computational simulations (Hedström 2005: Ch. 6; Manzo 2007; Hedström and Bearman 2009: 16), and, as implied by Manzo's (2014: 9) postulates 5-7 (see section 1.3) ended up with proposing “a complex interface among multivariate statistics, computational methods, mathematics, and experiments in which each method is mobilized to accomplish specific tasks" (Manzo 2014: 37). Moreover, the complementarity of methods pushed analytical sociology's methodological agenda to value the importance of combining different types of qualitative, quantitative, experimental, and small and big data with the ultimate goal of finding the best way to document the empirical traces of the postulated mechanisms (see Manzo 2014: 12, 37, 40; Manzo et al. 2018: 1146; Keuschnigg et al. 2018).

How do the substantive works that were awarded the Merton prize for illustrating analytical sociology at its best fit this picture? The second and third columns of Table I.3 provide a synthetic answer to this question, thus facilitating cross-article comparisons. In what follows I consider instead the methodology of each Merton awarded article in detail, again from the oldest to the most recent prize.

To study how different systems of political alliances emerge, Kroneberg and Wimmer (2012: 180, 187-9, 191, 193, 196) relied on a mathematical model that combines, on the one hand, an exchange model formalizing how actors form their preferences over possible alliance configurations and, on the other hand, a sequential, non-cooperative game model formalizing how negotiation between actors unfold. Crucial parameters of the exchange theoretic models, namely resource control and power, are based on "carefully researched historical data on the distribution of taxing capabilities, public goods provision, and military support in France (1300-1900) and the Ottoman Empire (1500-1900)" (ibid., 181-2), which, they claimed "prevent us from simply assuming the parameter values that will generate the hypothesized outcomes". Given this empirical calibration, Kroneberg and Wimmer (2012: 218) observed that the model was able to generate the rhythm and the outcome of political identities and alliances historically observed in France and the Ottoman Empire, namely more inclusive national building and less ethnic enclosures and status differentiation in the former case. That said, being aware that full empirical calibration and outcome validation was not possible for the long-term historical process of interest, Kroneberg and Wimmer (2012: 182-3, 201-2, 214, 217, and Appendix C) also performed extensive sensitivity analysis (on the empirical values adopted for the exchange model's parameters) and various robustness checks (on various model's assumptions, like the number of actors, the sequences of moves, political decisions, or the distributions of cultural traits), showing that results were qualitatively unchanged.

To demonstrate that the dependence of current choices on prior choices within homophilous social networks can lead to intergroup inequalities in internet adoption as well as to intervillage differences in Thai rural-urban migration rates, DiMaggio and Garip (2011) adopted 


\section{Research handbook on analytical sociology}

two different methods. In the former case, they designed an agent-based computational model depicting how ego's reservation price to adopt the Internet is impacted by others' choices (ibid., 1894). Crucial agent-level parameters (like the number of social contacts, income, race, and education) are based on US nationally representative survey data (ibid., 1900-1901). Given the inequality patterns by race and education observed in survey data between 1997 and 2007 (ibid., 1899), the model is simulated under different types of network externalities and varying levels of network homophily to establish which conditions led to aggregate outcomes that qualitatively resembled the observed ones (ibid., 1902 and ss.). Multivariate statistical models were estimated to describe the simulation results both at the agent- and system-level (ibid., 1908-1911). In the Thai case, DiMaggio and Garip (2011: 1916, 1920-1) attempted to find direct traces of the inequality effect of network homophily by exploiting detailed longitudinal survey data describing migration choices and flows from 22 migrant-sending villages between 1972 and 2000. To this aim, they performed both individual-level statistical analyses (namely, event history methods) and village-level analyses (namely, ordinary least squares models) on the empirical data. These models were submitted to a variety of sensitivity and robustness checks concerning variable measurement (in particular, village's social homogeneity) and models' specification (in particular, with respect to unmeasured village's attributes) (ibid., 1919, 1921).

To detect the relevance of macro signaling in generating gender stratification in job-specific skills, Polavieja (2012) combined mathematical and statistical modeling in the following way. First, he formalized investment decisions in jobs requiring learning new skills and formally established that “employees' investment choices will be crucially dependent on their expected duration in the firm" (ibid., 599). He postulated that individuals can estimate their job survival expectations for a given job by looking at others' experiences, namely, "the investment experiences of other women in preceding generations (hypothesis 1), the domestic behavior of men in their proximate social contexts (hypothesis 2), and the fertility behavior of peers (hypothesis 3)" (ibid., 600). Then, he estimated country fixed-effects regressions (with robust standard errors at the region level) on European Social Survey data (2004-2005) concerning 45, 600 individuals, nested in 234 different regions and 24 different countries, thus exploiting cross-country and cross-region, within-country variations (ibid., 594, 604, 612), and showed that the three contextual variables were all significantly associated with women's investments decisions in job-specific skills, whereas they had no effect for men (ibid., 616, 619, 621). This between-gender variation was ascertained by estimating the statistical models containing the social interaction effect separately for men and women (ibid., 612). Polavieja (2012) checked that results were robust against various controls for preference heterogeneity, different measures of job-skill specialization, potential regional collinearity, and alternative model's levels specification (ibid., 603, 607, 610, 612, 616-17).

To demonstrate the empirical relevance of attraction/rejection for/of similar/dissimilar others as a social mechanism for homophily in couple formation, Skvoretz (2013: 489, 495, 499-500) combined mathematical and statistical modeling in the following way. He first wrote down equations formalizing the probability of sequential tie formation as depending on (a) the opportunity of encountering similar/dissimilar others as simply the result of the demographic size of the groups considered; and (b) the actors' tendency to prefer similar others and reject dissimilar ones. As the opportunity part of the model only depends on the groups' size, and each of the two individual tendencies are represented by a single parameter, Skvoretz could then exploit empirical cross-tabulations (built from survey data) on marriages, 
dating, and cohabitation by race, ethnicity, religion, and education, computed to estimate the variation of the values of the two parameters expressing the individuals' bias for similar and dissimilar others across a variety of western countries. Skvoretz (2013: 500, 503) checked the robustness of his results by estimating the model on cross-tabulations artificially generated on the basis of known values of the attraction/repulsion parameters, and also studied model's extension contemplating various forms of inter-group variability in the attraction/repulsion motives.

To study the impact of within- and between-race income inequality on residential segregation by race given the size of race groups, Bruch (2014) articulated agent-based computational models and various multivariate statistical techniques. In particular, she first designed a simplified artificial society with a simplified geography where only artificial agents' residential mobility choices were empirically calibrated, namely through discrete choice conditional logit models estimated on US longitudinal data coming from the Panel Study of Income Dynamics. This first model was used to manipulate experimentally the group size and the level of within- and between-race income inequality (ibid., 1236, 1243). Then, by exploiting Census data, she made the same model more realistic by incorporating within the simulation the geography of three US cities, namely Los Angeles, Atlanta, and Chicago, as well as the temporal evolutions of income inequality and group size in these cities (ibid., 1245-6). Both versions of the computational model pointed to the same possible offsetting dynamics: decreasing between-race income inequality can lead to less isolation for poor blacks, but more isolation (from the black population) of wealthy blacks, the resulting aggregate net effect potentially being unchanged, or even higher, residential segregation (ibid., 1252, 1255). To check if "the model is providing inferences that accurately capture mechanisms at work in real cities" (ibid., 1256), Bruch finally estimated fixed-effects models at the metro area level for 93 major American cities between 1980 and 2000, which modeled segregation level changes in these cities as a function of changes in between- and within-race income inequality, as well as race group size. Traces of the offsetting mechanism that appeared within the simulations were also found in the empirical data described by the statistical models (ibid., 1264-5). Robustness checks concerning variable measurement and models' specification were frequent throughout the analyses (ibid., 1237, 1239, 1248).

To demonstrate that private experiences have different probabilities of traveling through social networks as a function of their stigmatizing potential, Cowen (2014) combined two different sources of empirical data. On the one hand, she designed a tailored internet-based survey investigating the attributes of American adults who were more likely to act as confidantes of women experiencing miscarriage and abortion (ibid., 467, 473, 478). After various controls and weighting procedures to assure national representativeness (ibid., 474), these data were described through logistic regressions modeling the respondents' probability of knowing someone who experienced the two events (ibid., 478). On the other hand, Cowen exploited qualitative data recording women's self-declared motivations for not disclosing miscarriage and abortion: these data came from a qualitative module contained in the Internet-based survey designed by the author herself, as well as from a unique data set containing information on 5000 women who experienced abortion at a US urban abortion clinic (ibid., 475). These qualitative data were used to provide direct empirical evidence that women disclosed their experience preferentially to those from whom they expected support rather than moral disapprobation, a tendency that is stronger as the amount of expected stigma for the event to be disclosed is higher (ibid., 481-2). 


\section{Research handbook on analytical sociology}

To document how variation in contextual traces of past (minor) norm violations leads to variation in further (minor) norm violation, thus explaining variations in norm compliance across contexts, Keuschnigg and Wolbring (2015: 103) mainly relied on the experimental approach. In particular, they designed three field experiments (in Munich) where each participant acted in a natural environment and was not aware of being part of an experiment. In the first experiment, littering was used as treatment to signal physical disorder, and subjects were tempted to further littering by finding a nonsense flyer attached to the handlebar of their bike (ibid., 104); in the second experiment, jaywalking was used as treatment to signal social disorder, and the subjects were tempted to same-norm violation by directly observing others' jaywalking at pedestrian lights (ibid., 109); in the third experiment, a lost letter showing a varying amount of money was used as treatment, and subjects were induced to fall in cross-norm violation, i.e. steal the letter after seeing physical disorder (namely, littering) (ibid., 112). All three experiments were set in locations with varying levels of social capital, measured either though tailored survey — for the first experiment (ibid., 106-7)—or through urban district-level data (ibid., 109-11). The statistical significance of differences between experimental conditions was measured through two-side chi-square tests (ibid., 114); a variety of small modifications in the experiment designs were tested to check the results' robustness, and the basic setup of the first and the third experiments was designed to allow replicability of previous experiments (ibid., 104).

To demonstrate that Muslim women may veil for strategic reasons, in particular as a way to signal their piousness when exposed to social contacts perceived as a potential threat to their moral integrity, Aksoy and Gambetta $(2016: 792,795)$ relied on two national surveys, one from Turkey and one from Belgium (where Muslims are a minority), as well as on a large-scale comparative dataset (the Pew World Muslims Survey) containing information on veiling in 25 Muslim countries in Africa, the Middle East, and Europe. Aksoy and Gambetta (2016: 794, 796) looked into these data with the aim of exploiting variation among women with different levels of religiosity, and among urban areas with various levels of veiling and dispersion in terms of types of veiling. To do so, they employed structural equation modeling (with ordinal probit regressions) treating the respondents' religiosity as a latent variables (ibid., 793, 797), and showed that, while the models' average main effects supported the predictions of the modernization theory (according to which veiling as a manifestation of religious beliefs should be lower among urban, educated, and employed Muslim women), interaction effects making veiling conditional on women's level of religiosity supported the signaling interpretation of veiling: when educated, urban, and middle-class women were highly religious, they veiled more than the average Muslim woman, and they tended to veil more when they lived in a neighborhood where the average level of veiling was lower, and the variety of its dressing expressions was high (ibid., 797, 798, 800). Various sensitivity tests, in particular with respect to missing values imputation and measures of veiling (ibid., 796, 800), were performed to check the results' robustness; secondary qualitative evidence was also described at various points of the analysis to support the mechanism narrative (ibid., 794, 803).

To show that patterns of clustered cultural preferences can emerge from the mechanism of "associative diffusion"-i.e. a sequence of events where actors progressively attach meanings to practices by observing co-occurrences of practices in others' observable behaviors - Goldberg and Stein (2018: 908) overtly followed the principles of agent-based models with "low-dimensional realism" according to which the computational model is used to determine the sufficient condition(s) under which a given macroscopic outcome can 
appear. In particular, Goldberg and Stein (2018: 899-901) wanted to show that, contrary to what was postulated by many existing works, cultural differentiation can appear even in the absence of selection on practices (so that actors preferentially interact with similar others), and/or network segmentation (which exposes actors only to subsets of practices). To this aim, they designed an artificial society in which (a) each agent possesses a (randomly initialized) vector of preferences for a set of practices, as well as a matrix of associations between these practices (initially all equally associated), (b) agents sequentially interact within random dyadic encounters during which one agent can observe two behaviors of the other agent, and (c) conditionally on interaction, the observer agent updates his matrix of associations between practices and, possibly, their preferences for the observed practices, as long as this contributes to reinforce positive associations between practices (ibid., 908-10). Goldberg and Stein (2018: 913-4) found that this minimal sequence of events is sufficient to gradually lead to stable associations of clustered practices. By further simulating alternative mechanisms (like biased contagion, conformist imitation, and homophily), they also show that none of these mechanism alone (i.e. in absence of network segmentation) is able to generate clusters of cultural practices (ibid., 916-17). As a by-product of these robustness checks, Goldberg and Stein (2018: 920) ultimately established that, if network segmentation is not a necessary condition for the emergence of cultural differentiation when "associative diffusion" is at work, specific network topologies, in particular scale-free-like networks, can generate "crisper" boundaries between clusters of cultural practices.

To document the extent to which adolescents' ethnic identification acts as a driver for ethnic homophily in school-based friendship networks, Leszczensky and Pink (2019: 397) relied on a well-tailored dataset containing three waves of network panel information collected on more than 2000 students in the 5th, 6th, and 7th grades of nine schools in nine towns in the federal state of North Rhine, Westphalia. On this basis they were able to reconstruct " 13 grade-level networks consisting of 1,349 students". Leszczensky and Pink (2019: 396-7) studied these networks through "stochastic actor-oriented models for network formation and behavior" (SAOM), which they explicitly compared to agent-based models by noting that SAOM also "assume that observed states are the result of an underlying process that consists of numerous micro-steps in which individuals either form, maintain, or dissolve ties or change their behavior" (ibid., 402). In addition, they claimed (ibid., 403-4) this type of statistical model allows us to assess the relative importance of preferences for similar others by controlling various structural constrains related to the underlying networks and potential social influence (i.e. changes in individual attributes due to tie formation itself). In particular, Leszczensky and Pink (2019: 404-5) are interested in assessing the relative weight of ethnic homophily (i.e. preference for same-ethnicity friends) conditional on ego and alter's level of ethnic identification, which they attempted to capture by specifying a two- and three-way interaction term respectively. It turned out that only the three-way interaction effect was statistically significant (ibid., 409), which the author interpreted as evidence that "ethnic homophily is not ubiquitous" but "arises as an interplay of ego's and alter's ethnic identification, requiring strong identification of both parties of the friendship" (ibid., 410). The robustness of this result was checked against various modifications of the variables' operationalization, and the statistical model's specification (ibid., 411).

Finally, to demonstrate that herding behavior can sustain self-correcting dynamics that make status hierarchies with quality/status decoupling only a transient state of the system, van de Rijt (2019) combined mathematical modeling and experiments. In particular, he first formalized 
discrete choices with uncertainty under social influence to clarify analytically the condition under which low-quality options can stably become more popular, the condition being, according to his model, that the low-quality option is chosen with a probability at least equal to the fraction of the population having chosen that option in the past (ibid., 1472). Then, van de Rijt (2019) considered six experiments that, in various settings and for different types for choices, found that others' behavior was able to distort actors' perception of the quality of the options at hand, thus leading low-quality options to be chosen more frequently than superior ones. By comparing the fraction of choices for the inferior alternative observed in each experiment with the condition for sustainable low-quality dynamics that he identified analytically, van de Rijt (2019: 1473-81) showed that none of these experiments in fact could prove that the fraction of choices for the low-quality options was sufficiently large to generate a stable decoupling of popularity from quality over time. With the aim of creating a sequence of interdependent choices long enough to have the potential to reverse entirely the initial dominance of lowquality alternatives, van de Rijt (2019: 1481) finally designed a novel large-scale, web-based experiment, through Amazon Mechanical Turk, including 5068 subjects, and varying the type of alternatives to be evaluated (ibid., 1483, fig. 2). The analysis of the 27,859 choices recorded showed that "[...] in all seven cases the initial 93\% advantage for A was fully eliminated over the course of the experiment and converted into majority support for B" (ibid., 1484). It is worth noting that van de Rijt (2019: 1487) also modified his experimental design to identify conditions under which popularity actually can be stably decoupled by quality, which allowed him to further demonstrate that these conditions are related to structural constrains rather than social influence deriving from herding behavior.

Thus, overall, Merton awarded articles clearly exhibited a large variety of methodological strategies to connect the explanans to the explanandum. With the exception of Goldberg and Stein (2018), all articles attempted to provide real-world evidence for the proposed mechanism(s), often combining various types of data. While individual-level survey data (in one case also containing ego-centered network information) were the most frequently exploited data, experimental data were at the heart of two studies, as well as qualitative data and historical archival data, respectively exploited by Cowen (2014) and by Kroneberg and Wimmer (2012). As to methods, the tendency also is to combine various methodological approaches. With the exception of Aksoy and Gambetta (2016), all articles combined various forms of formal modeling with different types of statistical models, and/or measurement devices, and/or data collection procedures specifically tailored to the explanatory purpose at hand.

It should be also noted that, when multivariate statistical models constituted the main tool to empirically trace the postulated mechanism(s) - like in Polavieja (2012), Cowen (2014), Aksoy and Gambetta (2016), and Leszczensky and Pink (2019) - the specification of statistical interaction effects is the main leverage to tackle traces of the mechanism in the data. This is an important point because one of the aspects of analytical sociology's original critique of the explanatory power of statistical models was precisely related to the observation that many regression-like models place more emphasis on the evaluation of the relative importance of main additive effects than on designing theoretically motivated statistical interactions between variables. In particular, in his contribution to Hedström and Swedberg's Social Mechanisms Sørensen (1998: 244) argued that the specification of these effects is the best way one can exploit statistical models to connect theory and empirics. As "statisticians and statistically oriented sociologists do not like interaction effects in regression models", Sørensen (1998: 245) observed, "[...] we miss out on sociological stories of great interest - how things differ 
between subgroups and contexts" (see also p.253). The Merton awarded articles that mainly relied on multivariate statistics clearly followed Sørensen's lesson.

A final remark should be devoted to agent-based computational simulations. As we have seen in sections 1.3 and 1.4, various commentators regretted the increasing emphasis that analytical sociology's manifestos put on this method. In particular, more extensively than others, Kalter and Kroneberg (2014: 109) argued that, by "elevating particular modelling or research techniques to foundational principles", and by overemphasizing "particular methodological tools at the expense of others", in particular "empirically calibrated agent-based models", analytical sociology takes the risk of turning into a "mechanism cult". Supposing that the risk is real, Merton awarded articles clearly showed that analytical sociology is far from being exposed to this danger. Agent-based computational modeling is the chief methodology of three out of eleven articles, namely DiMaggio and Garip (2011), Bruch (2014), and Goldberg and Stein (2018); Leszczensky and Pink (2019) can be considered a fourth case in that stochastic actor-oriented models (SAOM) are increasingly considered a specific form of agent-based models, combining empirical calibration and statistical estimation where the explanandum is a network configuration (see Snijders and Steglich 2015; Stadtfeld and Amati, this volume). Kroneberg and Wimmer (2012: 191f., 197) admitted the virtues of agent-based computational models to study explanations focusing on the micro-macro connection, but they did not employ it. Thus, while agent-based modeling is clearly part of the toolbox of some of the best articles in analytical sociology, for the moment, this perspective is not dominated by agent-based modeling.

\section{MERTON AWARDS' ACTION THEORY AND ANOMALOUS CONCEPTS}

We know now that the Merton awarded articles shared a common modus operandi. They all started with clearly identified macroscopic patterns or dynamics; they all explicitly pursued the goal of understanding how these system-level properties emerged; they all designed a set of hypotheses relating (collective) actors' motives to the context and the structure of interactions these actors were embedded in; they all argued that the sequential interdependence of those actions and interactions progressively constructed the system-level regularities and/ or dynamics of interest; and through various combinations of formal models, experiments, statistical methods, and (with one exception) various types of data, they attempted to document the empirical plausibility of the postulated mechanisms. The Merton awarded articles thus followed in practice the research path progressively designed by analytical sociology's manifestos that I discussed in section 1. The main difference concerns the fact that agentbased computational models are not systematically at the heart of the way the model of the postulated mechanism is connected to the explananda of interest. In terms of Manzo's (2014: 7-9) synthetic exposition of the analytical sociology's core (see section 1.3), this means that postulates 1 to 4 are always fully realized whereas postulates 5 to 7 are present only in a subset of articles.

In this section, I go back to the way the Merton awarded articles formulated their explanatory mechanism (see section 5, and, for a summary, Table I.2), zoom in on it, and investigate two specific points: first, the extent to which actors' actions were framed within rational choice theories (section 7.1); and, second, the extent to which parts of the proposed mechanism were 
designed by using "anomalous" elements, i.e. concepts, theories, or broader research perspectives that analytical sociology's manifestos either criticized or did not explicitly include within analytical sociology's basic toolbox (section 7.2).

Both aspects seem worthy of special attention. As we have seen in section 1.2, scholars of various confessions criticized analytical sociology's scope for being limited by analytical sociologists' supposedly adherence to rational choice theories of individual action (see, in particular, Abbott 2007a, Gross 2009, Little 2012); symmetrically, scholars who traditionally defended these types of micro-level theories have denied analytical sociology's originality because of its supposed commitment to these same theories of individual action (see, in particular, Opp 2013). Others, although sympathetic to the social mechanism movement, objected to analytical sociology its excessively narrow theoretical framework, in particular one that over-simplifies the "context" in which individual actions take place and downplay the role of "culture" (see Edling and Rydgren 2014, 2016). For these reasons, it seems to me important to assess how articles that were regarded as illustrating analytical sociology at its best locate within this critical space.

\subsection{Action Theory}

With respect to action theory, analytical sociology's programmatic writings progressively moved toward a more and more explicit pluralistic claim. Hedström and Swedberg's (1998: 11-13) discussed more explicitly methodological individualism than action theory per se. They mentioned once the intentional nature of human action (ibid., 12) as well as the fact that social action is typically oriented toward others (ibid., 13) but they did not commit the formulation of action-formation mechanisms to any specific theory of action (ibid., 23). The critique of the variants of rational-choice theory that model actors as computational devices looking for the best information available, and the optimal course of action allowing the maximization of subjective rewards, became explicit in Hedström (2005: 61); the associated critique of "instrumentalism" (i.e. the claim that, although unrealistic, the rationality assumption should not be removed because it may still lead to correct predictions in the aggregate, and/or because it would make formal models easier to study) led Hedström (2005: 61, 65-6) to propose to abandon rational-choice theory as a "general point of departure" for the micro level. Then, the observation that the various forms of "weak" or "subjective" rationality proposed by different authors to increase the realism of rational choice theory raise the problem of opening the way to ad hoc and post hoc explanations - see, in particular, Manzo's $(2012,2013)$ analysis of Boudon's theory of reasoned action and Opp's "broad" rational choice theory-progressively moved analytical sociology to question the idea itself of having a general theory of action to be used as a starting point for any explanatory task, no matter whether this theory is only weakly intentionally oriented or more strongly rationally oriented (Hedström and Ylikoski 2014: 65-7; see also Hedström 2021, this volume). Analytical sociology thus arrived to the programmatic statement, summarized in Manzo's (2014: 7) fourth postulate, see section 1.3), that a variety of logics of action - inspired by various versions of rational choice theories, dualprocess approaches, heuristic-based action theory, and action theories rooted in experimentally oriented cognitive and social psychology — are in principle all equally legitimate when specifying the micro-level component of a model of given mechanism; the conditions under which it is more realistic to assume this or that logic should be assessed on a case-by-case basis (see Manzo 2014: 21-7). 
Table I.3's fourth column synthetically shows that the Merton awarded articles fall in three distinct groups with respect to the rationality assumption. Four out of eleven studies - namely, Skvoretz (2013), Bruch (2014), Cowen (2014), and Leszczensky and Pink (2019)—simply did not refer at all to the concepts of rationality, utility, maximization, or strategy to frame the micro-level part of the proposed explanatory mechanisms. Linguistically, this translated to the virtual absence of these terms from the way the explanans is described. ${ }^{8}$

Three other articles — namely, Aksoy and Gambetta (2016), Goldberg and Stein (2018), and van de Rijt (2019) — did not contain any explicit statement, comment, or reference to rational action theory, but their explanans in practice refer to some forms of the rationality assumption. Aksoy and Gambetta (2016) is the most explicit in this sense in that, although no specific claim on rational choice theory is present, veiling is explicitly interpreted as a double strategic choice, namely "a strategy directed towards the self, and used as a self-binding device against temptation" (ibid., 794), and a strategy directed to others to signal "one's persisting piety" (ibid., 794). Goldberg and Stein (2018: 921-2) and van de Rijt (2019: 1470-1, 1475, 1483) are not that explicit, but both employed the term "utility" or "rationality" in conjunction with the aspect of their explanans referring, in the former case, to actors' heuristic of relying on others' co-occurrence of practices to reduce uncertainty about the meaning of those practices, and in the latter case, to actors' heuristic of relying on others' past choices to reduce uncertainty about the quality of a given option.

The last group is made of four articles - namely Keuschnigg and Wolbring (2015), Kroneberg and Wimmer (2012), Polavieja (2012) and DiMaggio and Garip (2011)—which explicitly explained the extent to which they adhere to some forms of rational action theory.

In particular, Keuschnigg and Wolbring (2015: 98) is the only article where the explanans is explicitly formulated through the terms and the concepts of rational choice theory: "we offer a rational choice explanation for norm violations in the context of environmental cues for the level of social control," the authors (overtly) claimed. However, as soon as this was posed, Keuschnigg and Wolbring (2015: 98) clarified that the theory that inspired them, i.e. the "Beckerian rational choice model of norm violating behavior" lacks realism in certain situations - "it appears to be unrealistic to assume that actors invest in costly search when breaking minor norms" (ibid., 99). In this case, they argued, "[...] environmental cues signaling social control gain in relevance. Hence, when individual costs and benefits are low it is rational to shorten the lengthy and cumbersome decision-making process by the use of heuristics". We know from section 5 that the heuristic proposed by Keuschnigg and Wolbring is that the traces of past behaviours in the actors' proximate environment are assumed to be the clue to form subjective beliefs on the probability of conviction. This is a form of rational imitation of others' behaviors. Social embeddedness is the second enrichment of the standard rational choice framework proposed by Keuschnigg and Wolbring (2015: 98, 102-3). They argue that the perceived level of social capital in a given neighborhood is also taken into account by a rational actor when deciding whether or not to violate a norm. In particular, if the social

\footnotetext{
8 One may want to consider Bruch (2014: 1237) as a borderline case in that she employed the term "utility" to express the intensity of the preference that a given actor associates to each residential neighborhood where she could potentially move. I am reticent to do so because the word "utility" is employed by Bruch only when she is presenting the dependent variable of discrete choice models to be statistically estimated, but she did not formulate any explicit behavioral interpretation of these models in terms of individual utility maximization. Thus I suspect that Bruch wanted to remain agnostic about the substantive meaning in action terms of the proposed logistic regression models.
} 
capital is perceived as low, the signaling force of traces of past deviating behaviors should be weaker-norm violations are perceived as common in this context anyway; vice versa, when the social capital is perceived as high, the signaling force of traces of past deviating behaviors should be high too - these traces suggest that norms can in fact be violated.

Kroneberg and Wimmer's (2012) study is also very close to rational choice theory. As we have seen, the explanans combines an exchange model of preference formation, where actors are assumed to prefer political alliances that maximize their control over political and economic resources (ibid., 190), with a non-cooperative sequential game of alliance formation. However, Kroneberg and Wimmer repeatedly emphasized the differences that exist between their approach and basic rational choice theory. First, they clarified that, in fact, they only assumed " $[. .$.$] — according to a weak version of standard rationality assumptions - that actors$ $\operatorname{did} \mathrm{X}$ because they wanted to achieve $\mathrm{Y}$, which is often the consequence of doing $\mathrm{X}[\ldots]$ " (ibid., 182). Second, with respect to the preference formation model, they emphasized that they went beyond a "purely instrumental approach" (ibid., 180), "purely utilitarian logic" (ibid., 187), and "instrumental interests" (ibid., 190), in particular, by adding "[...] an additional component into the model by letting actors consider with whom they can identify on the basis of cultural similarity when choosing alliance partners" (ibid., 180, see also pp. 187, 190 and 196). Third, with respect to the negotiation model, Kroneberg and Wimmer (ibid., 197) insisted on the fact that they "go beyond standard game-theoretic models that do not consider the unequal distribution of resources and treat the preferences of its players as exogenous-a major point of critique by scholars both sympathetic (Elster 2000) and unsympathetic to rational choice theory (Somers 1998)".

As to Polavieja (2012), his proposed explanans for women's under-investment in jobs requiring job-specific skills started with a representation of an actor's decision on the job market resulting from cost-benefit calculations. However, Polavieja (2012: 596) made it explicit that his goal is to show that these calculations " [...] are always and crucially influenced by the social structure in which individuals are embedded [...]". In particular, given the uncertainty surrounding the evaluation of job survival probabilities, the actions and the outcomes experiences of other actors in the actor's proximate social context provide clues to assess these probabilities: rational expectations can be formed through rational imitation (ibid., 603). Thus, similarly to van de Rijt (2019), Goldberg and Stein (2018), and Keuschnigg and Wolbring (2015), rational action finally takes the form of a simple heuristic: "if you are uncertain, follow others' behavior". Polavieja (2012: 622) explicitly acknowledged that "The idea that uncertainty and information constraints make individual choices more context dependent can be met by rationality assumptions of all strengths" (for a discussion, see Boudon (1996) and Goldthorpe (2000, Ch. 6)).

Finally, if DiMaggio and Garip's explanans (2011: 1888) is explicitly based on "goaldirected individual actions", they also made equally clear that they " $[\ldots]$ do not presume that choices are 'rational', either phenomenologically or in effect. People may adopt courses of action unreflectively, or they may adopt them on the basis of poor information about costs, benefits, and risks" (ibid., 1893, ft. 5). Again, action is represented as driven by a simple heuristic, namely to follow prior actions accomplished by the focal actor's direct contacts (ibid., 1888).

Thus, overall, the Merton awarded articles are clearly all committed to an actor-centered perspective. However, they do not uniformly rely on assumptions of rational choice theories to design the actor-related part of their explanatory machinery. Actors are never depicted as having optimal information and looking for subjective utility maximization. When individuals' 
actions are explicitly or implicitly depicted as rational, rationality is conceived as variously limited by the context, and usually take the form of heuristic-driven behaviors where the behaviors of others are exploited to reduce uncertainty about the quality, the risk, the attractiveness, or the meaning of the options under consideration.

\section{2 "Anomalous" Elements}

Table I.3's fifth column synthetically shows that the explanatory machinery of the Merton awarded articles also incorporated "anomalous" elements, i.e. concepts, theories, or broader research perspectives that analytical sociology's manifestos either criticized or did not explicitly include within analytical sociology's basic toolbox.

In this respect, the notions of "structure" and "context" are a first interesting case to be considered. Edling and Rydgren (2014: 1) admonished analytical sociology's manifestos for reducing social structures to "structures constituted of interacting individuals" as well as for giving priority micro-to-micro over macro-to-micro mechanisms. They urged analytical sociologists to consider that, in fact, "individuals' positions in the social structure, culture, as well as their identification with groups, social categories, and collectives, shape their beliefs and desires, and actions, in important ways" (Edling and Rydgren 2016: 1139).

Hedström's (2005: 17-18) critique of Blau's analysis of organizational differentiationwhich Hedström saw as "a direct precursor of his later so-called macro-sociological theory of social structure" - can partly explain this type of objections. In particular, Hedström remarked that Blau's style of theory construction equated the explanation of a fact to an operation of deduction of this fact from a hierarchy of propositions characterized by a decreasing level of abstraction and, given that these propositions are claimed to relate structural elements without making reference to individual-level properties, this type of theory construction is at odds with analytical sociology's ambition to open correlational black boxes (ibid., 19, 32).

Interestingly, among the Merton awarded articles, two studies - namely, Skvoretz (2013) and Bruch (2014) - framed their own contribution precisely within the context of Blau's theory of social structure or, more precisely, his analysis of how the composition of a given population impacts its inequality patterns. In particular, Skvoretz's (2013) model of homophily generation conceived individuals' attraction for similar others (and rejection of dissimilar others) as tendencies that bias the chance of encountering similar (dissimilar) others due to the simple sizes of the groups at stake. Skvoretz (2013: 487) overtly stated that this second aspect, i.e. the intuition that "some ties between similar others will form by chance and that the rate at which this occurs depends on the population distribution along the attribute of interest", is “[...] central to Blau's 1977 theory of social structure". However, Blau's central concern was "[...] how changes in overall population composition could create more or less opportunity for intergroup relations", noted Skvoretz (2013: 507); he wanted instead to understand more specifically the possible sources of inbreeding homophily (given baseline homophily). Skvoretz (2013: 487) noted again that Blau actually considered inbreeding homophily a "serious topic-because intergroup relations are necessary for societal level integration, yet inbreeding homophily inhibits their occurrence"-but he did not explore its underlying mechanism. Similarly, Bruch (2014: 1221) explicitly related her investigation of the interplay between race group's sizes, between- and within-race income inequality, residential choices, and residential segregation to one of the aspects of Blau's theory of social structure, namely the correlation that exists between levels of "consolidation" (i.e. the strength of the correlation 
between different attributes of the social structure) and social differentiation. Bruch (2014: 1222, see also p. 1228) noted that “[...] while Blau's original framework is compelling, it conflates two dimensions of the correlation between social attributes: within-attribute variation versus between-attribute variation", and she declared that her own goal is to "[...] extend Blau's work to investigate how choices about social grouping based on one attribute can exacerbate or attenuate segregation on another correlated attribute. The specific application is the role of racial and economic factors in generating patterns of racial residential segregation".

Thus, although both Skvoretz (2013) and Bruch (2014) seemed to ignore the skepticism that analytical sociology's manifestos expressed on the possible holist bias of Blau's theory of social structures, both studies in fact made some of the aspects of this theory compatible with well-specified social-mechanism-based explanations by turning structural elements into one of the parameters of individual choices, namely actors' opportunities.

"Social identity" is a second concept that some have argued being of high explanatory relevance while not being explicitly covered by analytical sociology's manifestos. In particular, with the aim of saving the predictive power of theories of rational action that equates "rationality" to "reason-based" behavior, Manzo (2012) argued that analytical sociology should pay more attention to individuals' social identities because identity often acts as a "reason trigger", i.e. an individual-level factor that tends recurrently to activate sets of specific reasons in specific contextual settings. Edling and Rydgren (2014) endorsed a more radical view. They regarded analytical sociology as still excessively biased toward intentional explanation (ibid., 2,5 ) and argued that one way to counteract this tendency would be to admit that "social actors also act out of identity, which comprises shared action potentials neither reducible to individual interests nor, in fact, to intentionality" (ibid., 10). They urged analytical sociology to pay special attention to "overlapping system of identifications" in which the individual's identity is instantiated and to study the conditions under which this or that social category acquires cognitive salience (ibid., 11-14).

Interestingly, among the Merton awarded articles, two studies-namely, Kroneberg and Wimmer (2012) and Leszczensky and Pink (2019) — overtly put actors' social identity at the heart of their explanatory machinery. In particular, Kroneberg and Wimmer (2012: 184) related their mechanism of alliance formation to identity formation and, by invoking "a long line of research in social psychology", they explicitly stated that "we assume that actors who enter into an alliance with each other will also develop a shared identity over time". This process is partly explained by the capacity of some actors to control cultural institution (like school or print media), thus allowing them to disseminate more effectively their "[...] vision of the legitimate divisions" of society, to paraphrase Bourdieu" (ibid., 194). These are the elements that brought Kroneberg and Wimmer to note that their model "[...] avoids the solipsistic bias that characterizes many formal models of individual identity choice", and that "[...] the model contributes to a growing literature that attempts to translate certain strands of the constructivist literature on nationalism and ethnicity into a formal modeling architecture [...]." At the same time, Kroneberg and Wimmer $(2012: 193,194)$ took the precaution of explaining that their model cannot be equated to "elite manipulation arguments" because all actors are represented to have control over some resources (masses, for instance, control "military support") so that "group formation and collective identities cannot be directly generated by force". Similarly, Leszczensky and Pink's (2019: 395) referred to social identity theory (in the tradition of Tajfel's work, one of the references also invoked by Kroneberg and Wimmer (2012: 398)) to better specify how individual preferences for similar others operate in the formation of 
ethnic homophily. In particular, their hypothesis that "ethnic identification" should be seen as a modifier of preferences for same-ethnicity friends is directly deduced from "social identity theory" that "[...] links the strength of ethnic identification to individual preferences" (ibid., 398) and "states that people strive for positive social identities, which they obtain by favorable comparisons of their own group with other groups" (ibid., 399). More particularly, Leszczensky and Pink's (2019: 398) built on "[...] the affective dimension of social identity, understood as the "emotional significance" individuals attach to their group membership [...]", which they considered the most important ingredient of ethnic identity when one wants to understand preferences for the in-group. Leszczensky and Pink (2019: 398) emphasized that they did not only rely on social identity theory, but extended this perspective through their network perspective focusing on "the interplay of two (potential) friends' ethnic identifications" (ibid., 411).

Finally, let me consider how different views of social interactions themselves penetrated the Merton awarded articles. In this respect, Erikson's (2013) typology of the theoretical frameworks underlying social network analysis turns to be very useful. In particular, she demonstrated that this field is animated by two broad perspectives that she synthetically labelled "formalism" and "relationalism". While the former sees "networks as pipes", i.e. structures of entities with stable and given identities constraining those entities' opportunities, beliefs and ultimately actions, the latter sees networks as culturally constructed and constantly moving objects with unstable boundaries and identities. Erikson (2013: 222-3, 236) noted the proximity between "relationalism", pragmatism, and cultural sociology and, more recently, she rightly added that analytical sociology has tended to treat social network analysis more from a "formalist" viewpoint than from a "relationalist" perspective (see Erikson 2017: 292-3).

Interestingly, among the Merton awarded articles, two of them-namely Cowen (2014) and Goldberg and Stein (2018) — clearly endorsed a "relationalist" perspective and overtly put subjective perceptions of social networks at the heart of their explanans. More particularly, when Cowen (2014) proposed to explain the temporal stability of attitudes toward abortion in terms of women's choices of selectively disclosing their private experiences as a function of the expected reaction of the potential confidante (using political attitudes as a clue to formulate such expectation), she explicitly claimed that her mechanism reverses the dominant perspective on the relation between actors' attitudes and networks: "Scholarship has already shown that social networks shape attitudes; I show that through secret keeping and sharing, attitudes shape individual experiences of social networks as well" (ibid., 484). In particular, she wanted to show that selective disclosure sustain a "self-fulfilling illusion"-i.e. "[...] those who are opposed to a given secret are less likely to hear of it even if it exists in their social vicinity" (ibid., 485) - so that homophily on opinions and behaviors does not exist in ego's local network but ego perceives it - "[...] ego can exist in a network where people do not hold a person's attitudes or behave as the person would like but the person mistakenly perceives that they do". It is precisely this falsely subjectively perceived lack of diversity that create the basis for the absence of opportunities for belief change and, consequently, opinion stability at the macro level.

Similarly, Goldberg and Stein's (2018) computational model of how clusters of cultural practices emerge in the absence of pre-existing network segmentation is overtly framed within a meaning-centered, cognitively rooted view of social structures:

In the theory we propose, rather than beliefs or behaviors per se, the cultural elements being transmitted between individuals are perceptions about which beliefs or behaviors are compatible with 


\section{Research handbook on analytical sociology}

one another [...]. Ultimately, our model turns the causal arrow in conventional accounts of social contagion on its head: we show that differentiation can emerge through the complex ways culture is cognitively represented and acted upon by individuals. (ibid., 898-9)

Goldberg and Stein (2018: 907) explicitly claimed that, whilst "[...] students of cultural diffusion have overwhelmingly left meaning out of their epidemiologically inspired models [...]", their alternative model of associative diffusion describes how "[...] arbitrary cultural meanings emerge and become consensually accepted through social interaction" and, in this sense, it describes a process of "social construction (Berger and Luckmann 1967)": "People do not simply imitate others' behaviors; rather, they learn, by observing others, what these behaviors mean". For this reason, Goldberg and Stein's (2018: 922) regarded their study as a contribution to both sociology of network and diffusion- - "[...] our associative model shifts focus from the diffusion of practices to the diffusion of interpretation - and to sociology of culture- $[\ldots]$ we demonstrate how meaning arises through the process of associative diffusion". 9

Thus, in six out of eleven Merton awarded articles, theories, concepts, or broader perspectives that were either criticized, or not explicitly considered as a part of the initial basic toolbox of analytical sociology, are explicitly employed to build well-specified mechanism-based explanations. The common point of these articles is that these "anomalous" elements are always conceptually unpacked so that the concept at hand-be that of structure, identity, or meaning - is never used as a pure label. This is achieved either through formalization, thus making the meaning and content of the concept clear and replicable by others (this is the case of Kroneberg and Wimmer, Skvoretz, Bruch, and Goldberg and Stein), or empirically measured through well-tailored data collection procedures (this is the case of both Cowen and Leszczensky and Pink's use of questionnaires to quantify stigmatization and ethnic identification respectively).

\section{SUMMARY OF THE ANALYSIS}

The main goal of this chapter was to provide a first comprehensive assessment of what analytical sociology looked like when scholars, inspired by its principles and methods, focused on solving specific substantive problems. To do so, I considered the eleven journal articles that have been awarded the Merton paper award (or an honorable mention for it), the prize the International Network of Analytical Sociology created in 2012 with the explicit intent of recognizing works that best illustrate analytical sociology's research practices. For this reason, although specific, this sample seems a natural starting point for a first assessment of the extent to which analytical sociology has so far practiced what it has preached. The members of the

\footnotetext{
9 Clear traces of a constructionist view of social structure can also be found in Leszczensky and Pink's (2019) study of mechanisms driving ethnic homophily. As we have seen, these authors deduced their main hypotheses from social identity theory. This same theory led them to regard ethnic groups from a subjective perspective - " [ [...] most studies on ethnic homophily treat ethnicity (or race) as a seemingly objective category rather than a potential source of social identity whose subjective importance varies both between and within individuals over time" (ibid. 395). They also explicitly argued for treating perceived group belonging as a relational process_- "[...] our relational social identity approach calls scholars to explicitly consider what being a member of a social group actually means [...]; doing so requires going beyond the individual level: a deeper understanding of how ingroup preferences unfold and structure diverse networks can only be obtained by considering the strength of ingroup identification of all parties involved in a social relationship" (ibid., 415).
} 
various prize committees (see Table I.1) were certainly sympathetic to the analytical sociology movement - if only because they were selected among participants to the INAS annual meetings or were suggested by those participants - but they clearly have different substantive, theoretical, and methodological personal agenda so that it was not a priori obvious whether a stable consensus on what analytical sociology is would appear across the prize's years.

To evaluate in a principled way the extent to which this was the case, the first section of the chapter was devoted synthetically to reconstruct the evolution of analytical sociology's principles and methods through analytical sociology's manifestos over the last twenty-five years. This preliminary analysis showed that analytical sociology progressively evolved toward a clearly codified research strategy organized around a well-defined sequence of research heuristics and steps. The set of seven postulates proposed by Manzo (2014: 7-9) to summarize this evolution of analytical sociology's programmatic agenda was then adopted as a benchmark in order to assess which principle and method was present, and how regularly, within the eleven Merton awarded articles.

This analysis generated three main general results concerning the general modus operandi of the Merton awarded articles and two additional observations concerning some specific aspect of this modus operandi.

General result 1-All Merton awarded articles started with a clear definition (typically provided in the article's introductory section) of a well-defined macro phenomena that they had the ambition to explain. These macro phenomena concerned an impressive range of structural properties and dynamics and could equally be a point of equilibrium of a social system, transitions from one equilibrium to another, dynamic flows, associations between contextual features and distribution of individual's attributes or choices, associations between population distributions, or properties of configuration of social ties. In each case, the article's goal was to explain the system-level patterns and/or dynamic, and explaining meant reaching an understanding of how the explanandum of interest was produced.

General result 2-To satisfy this explanatory goal, all Merton awarded articles designed a set of hypotheses, i.e. the explanans, systematically and consistently combined the three following ingredients: (a) a description of the specific pathways through which the context in which actors act shapes their beliefs, preferences, and/or opportunities; (b) the principles underlying actors' actions; and, (c) how action interdependency progressively generates the macro outcome of interest. In this sense, each awarded article designed a mechanism, i.e. a detailed description of a multi-level dynamic chains of events that, through specific action's logics and interdependence structures, is likely to lead to the system-level states and/or changes of interest.

General result 3-All Merton awarded articles attempted to prove that the explanans could plausibly and realistically lead to the explanandum. With only one exception, this was done by studying (most often) individual-level survey data, but also experimental, qualitative data, and/or historical archival data. As to methods, most of the articles combined various forms of formal modeling (including agent-based computational simulations) with different types of statistical techniques and/or measurement devices and/or data collection procedures specifically tailored to the explanatory purpose at hand. When multivariate statistical models constituted the main tool to tackle traces of the mechanism in the data, the priority was given to the specification of statistical interactions over the analysis of additive marginal effects.

Considered together, these three general results showed that all the eleven Merton awarded articles, in practice, followed analytical sociology's theoretical principles concern- 
ing how to define the research question, what constitutes a relevant explanandum, how to explain it, and what the structure of the explanation should basically contain. These elements correspond to postulates 1 to 4 of the analytical sociology's core research strategy, as synthetically defined by Manzo (2014: 7-9). In contrast, methodological postulates 5 to 7 , emphasizing the power of agent-based computational modeling as a pivotal tool to reconstruct the explanandum in a generative way, only found partial application. While four out of the eleven Merton awarded articles exploited this approach to create the explanandum/ explanans connection, the majority of them relied on more traditional statistical and, in two cases, experimental methods.

As anticipated, the careful investigation of the Merton awarded articles also generated two more specific observations on how analytical sociology was realized in substantive works.

Specific observation 1-Although all the Merton awarded articles are clearly committed to an actor-centered perspective, they did not uniformly rely on assumptions of rational choice theories to design the actor-related part of their explanatory machinery. Actors were never depicted as having optimal information, or looking for subjective utility maximization. Rationality was always conceived as variously limited by the context and usually took the form of heuristic-driven behaviors, where the behaviors of others were presented as a solution to reduce the uncertainty surrounding the evaluation of the options under consideration.

In this sense, the Merton awarded articles instantiated analytical sociology's call for action theory pluralism - i.e. the claim that, if we agree on the goal of achieving realistic explanation, then there is no theoretical nor empirical reason to consider a given theory of action as the obliged starting point for the model building stage (see Manzo 2014: 21-7; Hedström and Ylikoski 2014; see also Hedström 2021, this volume).

Specific observation 2-A consistent proportion of the Merton awarded articles (namely, six out of eleven) was capable of integrating within the proposed well-specified explanatory machinery, theories, concepts, or broader perspectives that analytical sociology's manifestos either criticized or did not explicitly consider part of the initial basic toolbox of analytical sociology-like Blau's theory of social structure, social-psychology works on social identity, and meaning-centered perspectives on network analysis, inspired by pragmatist and cultural sociology (see also Barbera 2021, this volume).

In this sense, the Merton awarded articles demonstrated in practice that analytical sociology can face the challenged formulated some years ago by Edling and Rydren (1994: 10), who argued that

in order to prove itself, analytical sociology will have to take seriously some of the "soft" ideas that are at the (mainstream) core of sociology such as culture and identity. We claim that there is no lack of sources of inspiration in the literature, and that culture and identity can be dealt with within the confines of analytical sociology and in fact serve to improve it.

\subsection{Five Guidelines and the Present Research Handbook}

To conclude, I would like to exploit the results and observations I just summarized to formulate five guidelines for the further development of the analytical sociology's research program. The Merton awarded articles, in fact, also contained elements that can be used to pinpoint aspects of the practice of analytical sociology on which we could/should continue to work. In particular, I detected five important lines of evolution for the future, to which the present Research Handbook intends to contribute. 
Guideline 1-Be explicit about whether your substantive investigation is related to the analytical sociology program and, if so, be clear about what theoretical and methodological principle(s) are you following, challenging, or refining.

While the Merton awarded articles followed the theoretical principles of analytical sociology's manifestos and, to a large extent, the methodological ones (the partial exception being a limited use of agent-based computer simulations), the majority did not explicitly refer to analytical sociology's manifestos to frame their substantive investigations and methodological recipes. All the articles widely relied on concepts, models, and typical mechanisms that analytical sociology's manifestos recurrently regarded as founding pieces of the analytical sociology's toolbox, but explicit and systematic use of the label "analytical sociology" was rare and systematic confrontation with the programmatic texts was virtually absent. While this choice can be regarded as a virtuous sign that, contrary to what critics sometimes claimed (see Chattoe-Brown 2014), analytical sociology is not a "self-regarding club," one should appreciate that this lack of explicit programmatic elaboration on the extent to which a given piece of work adheres to a given research program can have two potentially damages. First, substantively, this slows down analytical sociology's capacity to refine and enrich its own theoretical and methodological principles. Second, institutionally, not referring to analytical sociology's research program when one is using it diminishes analytical sociology's visibility and distinctiveness, thus further reducing the probability that others may want explicitly to refer to this perspective when, in fact, using it. Making explicit the adherence to a research program emphasizing a loop between clarity, precision, explanations fighting black boxes, formal models, and innovative data collection procedures seems especially important in a time where the legitimacy of the project of sociology as a science is strongly challenged by competing intellectual projects variously equating sociology to academic-based political activism (see Turner 2019; Romero 2020).

Guideline 2-Be explicit about how you use the concept of mechanism and how your own mechanism(s) relate to those that have been previously elaborated.

Each Merton awarded article provided a detailed description of a multi-level dynamic chains of events sustained by specific contextual constrains, action's logics, and interdependence structures. In this sense, they all escape without ambiguity to what Kroneberg and Kalter (2014: 100-2) called "mechanism talk"-i.e. various types of poorly explicated explanatory machineries like "pseudo mechanisms" (where "mechanism is just another word for the phenomenon of interest"), "ad hoc mechanisms" (descriptions, story-telling or interpretation lacking "evidence that the processes indeed show some generality and do indeed apply under the given conditions"), "rudimentary mechanisms" (reference to generic concepts without "further details on the bridge hypotheses, the action theory, and the transformation rules" or reference to "intervening variables that are mistakenly seen to 'explain' the presumed causal effect of an independent variable on a dependent one"), or "partial mechanisms" (simple references "to broad theoretical models or approaches"). At the same time, I observed that the majority of articles employed the term "mechanism" without defining it explicitly, and did not refer to typologies of mechanisms proposed by analytical sociology's manifestos. One should appreciate that this constitutes a considerable threat to knowledge accumulation by making the comparison of mechanisms across studies more difficult. A concrete example of this problem is given by the six (out of eleven) Merton awarded articles that postulated various forms of 
dependence between the focal actor's choice and prior choices of actors the focal actor can see, either through their social ties or through the aggregate. Only one article explicitly referred to the concept of "rational imitation"; none of them explicitly located this specific part of the larger explanatory mechanism postulated within analytical sociology's typologies of how social interactions may impact the various actions' components. This does not facilitate mechanism comparison, but obliges the reader to guess the specific channel (opportunity, preferences, or desires?) and the specific mode (rational or automatic?) through which the dependence across actors' actions is assumed to operate; this reduces the possibility to see that similar mechanisms are shown to be at work in different contexts and for different macroscopic phenomena.

Guideline 3-Be explicit about the type of action theory that informs the micro-level part of the proposed mechanism and, more particularly, be explicit about whether some form of rationality is postulated for individuals' actions.

The Merton awarded articles uniformly adopted weak forms of rationality and/or various forms of heuristic-based behaviors. This is in line with analytical sociology's skepticism about the possibility of using the same action theory as the general starting point for any modeling exercise. At the same time, only a minority of articles explicitly explicated the extent to which the micro level part of the proposed mechanism fits into rational action theories. Again, this lack of explicit theoretical elaboration threatens knowledge accumulation. In particular, it slows down the empirical understanding of the conditions under which strong and weak rationality assumptions hold and, more generally, when different types of action logics are more likely to be realistic. I observed that several Merton awarded articles explicitly identified the level of uncertainty as a crucial aspect to determine how strongly rationality can be assumed to operate. Others are silent on this point, however. For instance, when Cowen (2014) predicated selective disclosure on women's desire to avoid social stigma, was she assuming that women act strategically to preserve their reputation? Or, are women supposed to react emotionally and out of reflection? Or, still, when both logics are present in this case, what type of combination of "hot" and "cold" reasons is the modeler postulating? This is the type of question that we could progressively answer empirically if the assumptions one makes at the micro level were explicitly discussed in connection with the empirical phenomenon under investigation. Being clear on what program of action theory, "weak" or "strong" (see Kroneberg and Tutic, this volume; see also Hedström, this volume), one is following, and making the effort of unpacking broad concepts like uncertainty (see Ermakoff 2017; Ermakoff 2021, this volume) should help to go further into this direction.

Guideline 4-Be explicit about the concepts and theoretical perspectives that you bring into the analytical sociology's research program, about why you want to do so, and about how you do it.

Several Merton awarded articles built part of their explanatory machinery by relying on theories, concepts, or broader theoretical perspectives that were either criticized or not explicitly considered as a part of the initial basic toolbox of analytical sociology by analytical sociology's manifestos. This fact can see as the strongest indicator that, contrary to what some critics claimed (see Chattoe-Brown 2014), analytical sociology is far from being a "self-regarding club". When specific substantive problems are at stake, scholars following analytical sociology's principles turned out to be pragmatic: they picked up theoretical ingredients that seemed 
empirically adequate to deepen the explanation. Merton awarded articles that engaged with the concepts of structure, of social identity, or of meaning did so under a specific constrain: the concept is never used as a broad covering label. Either through formalization or well-tailored data collection procedures, the content of the concept, and its implications are clearly specified (see also Hedström, this volume). Once again, however, this operation of theoretical enrichment is more implicit than explicit. None of the Merton articles that built on concepts or theoretical perspectives that analytical sociology's manifestos did not cover initially did so with explicit reference to analytical sociology. This has two potentially undesirable consequences. On the one hand, it makes less visible analytical sociology's theoretical openness; on the other hand, it makes less visible analytical sociology's capacity to make transparent theoretical constructs that social theory has traditionally tended to treat as too rich to be formalized and/or quantitatively measurable. Analytical sociologists who intend to bring "anomalous" concepts or theories within analytical sociology should do this explicitly and systematically. An effective example to follow is Jaeger and Breen (2016) where Bourdieu's theory of cultural reproduction is formalized with the overtly displayed goal of making it clearer and equipped with solid micro foundations, and then challenged through empirical data.

Guideline 5-Be explicit about the extent to which each component of the proposed explanatory mechanism can be really studied through the data and the methods you decide to employ in order to connect the explanans to the explanandum.

All Merton awarded articles attempted to prove that the explanans could plausibly and realistically lead to the explanandum through various combinations of formal modeling, statistical techniques, large-scale datasets, and/or original data collection procedures specifically tailored to the explanatory purpose at hand. However, the specific methodological procedure adopted by some did not allow to document empirically all the ingredients of the proposed explanatory mechanism. While all the Merton awarded articles conceptually formulated a mechanism clarifying how the context constrains actors' action, the principles driving actors' actions, and how the actors' actions are interdependent, some articles relied on methods that could not explicitly represent this last component of the proposed mechanisms. Analytical sociology's manifestos progressively emphasized agent-based computational models as a flexible tool to formalize how interdependently constrained behaviors construct a given macroscopic outcome sequentially and dynamically. Some Merton awarded articles demonstrated that in field experiments, large-scale experiments run through the web, and individual-level longitudinal data combined with ego-network information can also be exploited to create, and document empirically, an aggregative dynamic, thus clearly indicating under which conditions dynamic interdependent actions can generate a given macroscopic fact or trend. In contrast, the Merton awarded articles that mainly relied on cross-sectional, individual-level survey data analyzed through multivariate statistics - think in particular of Polavieja (2012), Cowen (2014) and Aksoy and Gambetta (2016) — were strong in documenting empirically the macro-to-micro and the micro-to-micro part of the proposed mechanisms, in particular showing how various contextual and individual-level attributes changed the probability of certain individual-level outcomes, but they were incapable to formalize, nor document, whether the combination of those outcomes in fact led to the macroscopic outcome of interest, be that gender inequality, patterns of opinions, or clusters of religious behaviors. Makovi and Winship's (Figures 20.1 and 20.2, this volume) representation of Aksoy and Gambetta's and Cowen's explanatory mechanisms 
through the variable-centered perspective of directed acyclic graphs (DAGs) powerfully illustrate this point in very effective graphical terms. The danger of this is proposing verbal narratives involving the micro-macro links without explicitly documenting under which conditions the postulated aggregation process can lead to the system-level outcome of interest. Being more explicit about what component of the proposed explanatory mechanism of the method we can represent and document would help analytical sociology identify potential gaps in the proposed explanations, thus progressively increasing explanatory depth itself.

The present Research Handbook has the ambition to contribute to the further development of analytical sociology along these guidelines. In particular, the chapters included in the first part of the book aim to further clarify analytical sociology's principles, paradigmatic antecedents, and borders. In this sense, these chapters share the common goal of contributing to fulfill guidelines 1 and 4. This is done in three different, but complementary, ways. First, some of analytical sociology's fundamental conceptual tools, like the Coleman boat (Chapter 1) as well as some aspects of analytical sociology's historical roots like analytical Marxism and analytic philosophy (Chapter 2) and structural individualism (Chapter 3) are reconsidered. Second, similarities and differences with potentially closed research fields, like complexity science (Chapter 4) and social stratification research (Chapter 5), are explored. Finally, a more explicit comparison is performed between analytical sociology and theoretical perspectives like critical realism (Chapter 6), cultural sociology (Chapter 7), and pragmatism (Chapter 8) that are in principle more distant from analytical sociology.

The chapters included in the second part of the book aim more specifically at increasing knowledge accumulation within analytical sociology, and to favor mechanism comparison. In this sense, they all pursue guideline 2 . They do so in two different but complementary ways. On the one hand, they overview how analytical sociology has treated basic conceptual building blocks for designing models of mechanisms, in particular individuals' actions (Chapter 9), dyadic interactions (Chapter 10), network structures (Chapter 11), norms (Chapter 12), larger contexts (Chapter 13) as well as generic elements shared by all these building blocks like contingency and randomness (Chapter 14). On the other hand, some chapters systematize what we know about generic mechanisms that have been especially studied by analytical sociologists, which include cumulative advantage mechanisms (Chapter 15), phenomena of network amplification (Chapter 16), and complex contagions (Chapter 17). By providing conceptual coordinates for action theories, Chapter 9 also contributes more specifically to guideline 3.

Finally, the chapters included in the third part of the book have the goal of increasing analytical sociologists' awareness of how various types of data and methods can specifically contribute to formalize and document empirically social mechanisms. In this sense, they all have the common goal of contributing to guideline 5. In particular, as to data, I gave priority to information that has been less frequently exploited by analytical sociologists, in particular historical and qualitative, as well as numerical archival data (Chapter 18), and various types of digital traces (Chapter 19). As to methods, I wanted to cover both methods putting a strong emphasis on causal inference like mediation analysis (Chapter 20) and experiments (Chapter 21) and methods focusing on dynamics and generativity like game theory (Chapter 22), network models (Chapter 23), and agent-based simulations (Chapter 24). To stress the complementarity of these resources to represent and document a given social mechanism, a claim for a many model approach is finally examined in Chapter 25 . 
In conclusion, Hedström's Coda provides a personal reflection on various aspects of the past and the future of analytical sociology by focusing especially on whether, and, if so, under which conditions intentional explanations should still be regarded as a crucial step for the construction of empirically plausible models of social mechanisms, thus provocatively contributing to guideline 3 .

\section{REFERENCES}

*Articles which received the Merton Award for the best paper in analytical sociology

Abbott A. (2007a), "Mechanisms and Relations", Sociologica, 2.

Abbott A. (2007b), "Mechanisms and Relations: A Response to the Comments", Sociologica, 2.

*Aksoy O., and D. Gambetta (2016), "Behind the Veil: The Strategic Use of Religious Garb", European Sociological Review, 32, 6: 792-806.

Barbera F. (2012), "Meso-Level Mechanisms and Micro-Level Foundation”, Sociologica, Italian Journal of Sociology On Line, 1. https://doi.org/10.2383/36899.

Boudon R. (2012), "'Analytical Sociology' and the Explanation of Beliefs". Revue européenne des sciences sociales, 50, 2: 7-34.

Bouvier (2018). "Intentional, Unintentional and Sub-intentional Aspects of Social Mechanisms and Rationality: The Example of Commitments in Political Life", in G. Bronner and F. Di Iorio (eds), The Mystery of Rationality. Mind, Beliefs, and the Social Sciences, Cham (Switzerland): Springer, Ch. 3.

*Bruch E. (2014), "How Population Structure Shapes Neighborhood Segregation", American Journal of Sociology, 119, 5: 1221-78.

Chattoe-Brown E. (2014), "Review of Analytical Sociology: Actions and Networks", Journal of Artificial Society and Social Simulation, 17, 4. http://jasss.soc.surrey.ac.uk/17/4/reviews/1.html.

*Cowen S.K. (2014), "Secrets and Misperceptions: The Creation of Self-Fulfilling Illusions", Sociological Science, 1: 466-92.

Demeulenaere, P. (2011), "Introduction”, in P. Demeulenaere (ed.), Analytical Sociology and Social Mechanisms, Cambridge, UK: Cambridge University Press, pp. 1-30.

*DiMaggio P., and F. Garip (2011), "How Network Externalities Can Exacerbate Intergroup Inequality", American Journal of Sociology, 116, 6: 1887-933.

Edling C., and J. Rydgren (2014), "Analytical Sociology: Bringing Culture and Identity Back In”, Sociologica, 2. https://doi.org/10.2383/78818.

Edling C., and J. Rydgren (2016), "Social Mechanisms in Empirical Sociology: Introduction to Special Issue", American Behavioral Scientist, 60, 10: 1135-45.

Erikson E. (2013), "Formalist and Relationalist Theory in Social Network Analysis", Sociological Theory, 31, 3 : 219-42.

Erikson E. (2017), "Networks and Network Theory: Possible Directions for Unification", in C.E. Benzecry, M. Krause, and I.A. Reed (eds), Social Theory Now, Chicago: University of Chicago Press, pp. 278-305.

Ermakoff I. (2017), "On the Frontiers of Rational Choice", in C.E. Benzecry, M. Krause, and I.A. Reed (eds), Social Theory Now, Chicago: University of Chicago Press, pp. 162-200.

*Goldberg A., and S.K. Stein (2018), "Beyond Social Contagion: Associative Diffusion and the Emergence of Cultural Variation", American Sociological Review, 83, 5: 893-932.

Gross N. (2009), “A Pragmatist Theory of Social Mechanisms”, American Sociological Review, 74: 358-79.

Hedström P. (2005), Dissecting the Social: On the Principles of Analytical Sociology, Cambridge, UK: Cambridge University Press.

Hedström P., and P. Bearman (2009), "What is Analytical Sociology all about?”, in P. Bearman and P. Hedström (eds), The Oxford Handbook of Analytical Sociology, Oxford, UK: Oxford University Press, Ch. 1.

Hedström P., and G. Manzo (2015), "Recent Trends in Agent-Based Computational Research: A Brief Introduction", Sociological Methods and Research, 44, 2: 179-85.

Hedström P., and R. Swedberg (1996), "Social Mechanisms", Acta Sociologica, 39, 3: 281-308.

Hedström P., and R. Swedberg (eds) (1998a), Social Mechanisms: An Analytical Approach to Social Theory, Cambridge UK: Cambridge University Press.

Hedström P., and R. Swedberg (1998b) "Social Mechanisms: An introductory Essay", in Social Mechanisms. An Analytical Approach to Social Theory, Cambridge UK: Cambridge University Press, Ch. 1.

Hedström, P. and L. Udehn (2009), “Analytical Sociology and Theories of Middle-Range”, in P. Bearman and P. Hedström (eds), The Oxford Handbook of Analytical Sociology, Oxford, UK: Oxford University Press, Ch. 2. 
Hedström P., and P. Ylikoski (2014), “Analytical Sociology and Rational-Choice Theory, in G. Manzo (ed.), Analytical Sociology: Actions and Networks, Chichester, UK: Wiley, pp. 53-70.

Jaeger M.M., and R. Breen (2016), “A Dynamic Model of Cultural Reproduction”, American Journal of Sociology, 121, 4: 1079-1115.

Kalter F., and C. Kroneberg (2014), "Between Mechanism Talk and Mechanism Cult: New Emphases in Explanatory Sociology and Empirical Research", in J. Friedrichs and A. Nonnenmacher (eds), Kölner Zeitschrift für Soziologie und Sozialpsychologie, Special Issue 54: Social Contexts and Social Mechanisms: 91-115.

Keuschnigg M., N. Lovsjö, and P. Hedström (2018), "Analytical Sociology and Computational Social Science", Journal of Computational Social Science. https://doi.org/10.1007/s42001-017-0006-5.

*Keuschnigg M., and T. Wolbring (2015), "Disorder, Social Capital, and Norm Violation: Three Field Experiments on the Broken Windows Thesis", Rationality and Society, 27, 1: 96-126.

Kim, Lanu, C. Adolph, J.D. West, and K. Stovel (2020), "The Influence of Changing Marginals on Measures of Inequality in Scholarly Citations: Evidence of Bias and a Resampling Correction", Sociological Science, 7: 314-41.

*Kroneberg C., and A. Wimmer (2012), "Struggling Over the Boundaries of Belonging. A Formal Model of Nation Building, Ethnic Closure, and Populism”, American Journal of Sociology, 118, 1: 176-230.

*Leszczensky L., and S. Pink (2019), "What Drives Ethnic Homophily? A Relational Approach on How Ethnic Identification Moderates Preferences for Same-Ethnic Friends", American Sociological Review, 84, 3: 394-419.

Little D. (2012), "Analytical Sociology and the Rest of Sociology", Sociologica, 1. https://doi.org/10.2383/36894.

Lizardo O. (2012), “Analytical Sociology's Superfluous Revolution: Comment on Little, Sociologica, 1. https://doi .org/10.2383/36902.

Manzo G. (2007), "Variables, Mechanisms, and Simulations: Can the Three Methods Be Synthesized? A Critical Analysis of the Literature, Revue Française de Sociologie, 48, 35-71.

Manzo G. (2010), “Analytical Sociology and its Critics”, European Journal of Sociology, 51, 1: 129-70.

Manzo G. (2011), "The Whole Is Greater Than the Sum of Its Parts: Some Remarks on the Oxford Handbook of Analytical Sociology", European Sociological Review, 27, 6: 829-35.

Manzo G. (2012a), "Full and Sketched Micro-Foundations: The Odd Resurgence of a Dubious Distinction", Sociologica, 1. https://doi.org/10.2383/36900.

Manzo G. (2012b), "Reason-Based Explanations and Analytical Sociology: A Rejoinder to Boudon", European Journal of Social Sciences, 50, 2: 35-65.

Manzo G. (2013), "Is Rational Choice Theory Still a Rational Choice of Theory?", Social Science Information, 52, 3: $361-82$.

Manzo G. (2014), "Data, Generative Models, and Mechanisms: More on the Principles of Analytical Sociology", in G. Manzo (ed.), Analytical Sociology: Actions and Networks, Chichester, UK: Wiley, pp. 4-52.

Manzo G., and D. Baldassarri (2015), "Heuristics, Interactions, and Status Hierarchies: An Agent-Based Model of Deference Exchange", Sociological Methods and Research, 44, 3:329-87.

Manzo G., S. Gabbriellini, V. Roux, and F.N. M'Mbogori (2018), "Complex Contagions and the Diffusion of Innovations: Evidence From a Small-N Study", Journal of Archaeological Method and Theory, 25, 4: 1109-54.

Marchionni C., and P. Ylikoski (2013), "Generative Explanation and Individualism in Agent-Based Simulation, Philosophy of the Social Sciences, 43, 3: 323-40.

Mayntz R. (2004), "Mechanisms in the Analysis of Macro-Social Phenomena", Philosophy of the Social Sciences, 34, 2: 237-59.

Morgan S.L. (2005), On the Edge of Commitment: Educational Attainment and Race in the United States, Stanford, CA: Stanford University Press.

Norkus Z. (2005), "Mechanisms as Miracle Makers? The Rise and the Inconsistence of the 'Mechanismic Approach' in Social Science and History", History and Theory, 44: 348-72.

Opp K.-D. (2005), "Explanations by Mechanisms in the Social Sciences. Problems, Advantages, and Alternatives", Mind and Society, 4, 2: 163-78.

Opp K.-D. (2007), "Peter Hedström: Dissecting the Social. On the Principles of Analytical Sociology", European Sociological Review, 23, 1: 115-22.

Opp K.-D. (2013), "What Is Analytical Sociology? Strengths and Weaknesses of a New Sociological Research Program", Social Science Information, 52, 3: 329-60.

*Polavieja J. (2012), "Socially-Embedded Investments: Explaining Gender Differences in Job-Specific Skills", American Journal of Sociology, 118, 3: 592-634.

Romero M. (2020), "Sociology Engaged in Social Justice", American Sociological Review, 85, 1: 1-30.

Reiss J. (2007), "Do We Need Mechanisms in the Social Sciences", Philosophy of the Social Sciences, 37, 2: $163-84$.

Sawyer R. Keith (2007), "Peter Hedström: Dissecting the Social. On the Principles of Analytical Sociology", Philosophy of the Social Sciences, 37: 255-60.

Snijders Tom A.B., and Christian E.G. Steglich (2015), "Representing Micro-Macro Linkages by Actor-Based Dynamic Network Models", Sociological Methods and Research, 44, 2: 222-71.

Sørensen A. (1998), "Theoretical Mechanisms and the Empirical Study of Social Processes", in P. Hedström and 
R. Swedberg (eds), Social Mechanisms: An Analytical Approach to Social Theory, Cambridge, UK: Cambridge University Press, pp. 238-66.

Steel D. (2004), "Social Mechanisms and Causal Inference", Philosophy of the Social Sciences, 34, 1: 55-78.

*Skvoretz J. (2013), "Diversity, Integration, and Social Ties: Attraction versus Repulsion as Drivers of Intra- and Intergroup Relations", American Journal of Sociology, 119, 2: 486-517.

Turner J.H. (2019), “The More American Sociology Seeks to Become a Politically-Relevant Discipline, the More Irrelevant It Becomes to Solving Societal Problems", The American Sociologist, 50: 456-87.

*van de Rijt A. (2019), "Self-Correcting Dynamics in Social Influence Processes", American Journal of Sociology, 124, 5: 1468-95.

Van Noorden R., B. Maher, and R. Nuzzo (2014), “The Top 100 Papers”, Nature, 514, 7524: 550-3. https://doi .org/10.1038/514550a.

Winship C., and Morgan, S.L. (2014), Counterfactuals and Causal Inference: Methods and Principles for Social Research, 2nd edition, Cambridge, UK: Cambridge University Press.

Ylikoski P. (2012), "Micro, Macro, and Mechanisms", in H. Kincaid (ed.), The Oxford Handbook of Philosophy of Social Science, Oxford, UK: Oxford University Press, pp. 21-45.

Ylikoski P. (2013), "The (Hopefully) Last Stand of the Covering-Law Theory: A reply to Opp", Social Science Information, 52, 3: 383-93. 